UNIVERSIDADE DE SÃO PAULO

FACULDADE DE MEDICINA DE RIBEIRÃO PRETO

\title{
ANÁLISE DE BIOMARCADORES E DÉFICIT COMPORTAMENTAL ASSOCIADOS À DOENÇA DE ALZHEIMER EM UM MODELO ANIMAL DE PREDISPOSIÇÃO GENÉTICA À EPILEPSIA
}

Aluno: Israel Costa Vasconcelos
Orientador: Prof. Dr. Adriano Silva Sebollela
Co-orientador: Prof. Dr. Norberto Garcia Cairasco

Ribeirão Preto/SP 


\section{ANÁLISE DE BIOMARCADORES E DÉFICIT COMPORTAMENTAL ASSOCIADOS À DOENÇA DE ALZHEIMER EM UM MODELO ANIMAL DE PREDISPOSIÇÃO GENÉTICA À EPILEPSIA.}

Dissertação apresentada ao Departamento de Bioquímica e Imunologia da Faculdade de Medicina de Ribeirão Preto/Universidade de São Paulo para obtenção do título de Mestre em Bioquímica.

Área de concentração: Bioquímica

Orientador: Prof. Dr. Adriano Silva Sebollela

Co-orientador: Prof. Dr. Norberto Garcia Cairasco

Ribeirão Preto/SP 


\section{FICHA CATALOGRÁFICA}

Vasconcelos, Israel Costa

Análise de biomarcadores e déficit comportamental associados à doença de Alzheimer em um modelo animal de predisposição genética à epilepsia.

Orientador: Sebollela, Adriano

Co-orientador: Garcia-Cairasco, Norberto

1. cepa WAR. 2. Alzheimer. 3. Epilepsia. 4. Comorbidades. 5. Tau. 6. Hiperfosforilação. 7. cognição 
VASCONCELOS, Israel Costa. Análise de biomarcadores e déficit comportamental associados à doença de Alzheimer em um modelo animal de predisposição genética à epilepsia. 2017. Dissertação (Mestrado em Bioquímica) - Faculdade de Medicina de Ribeirão Preto, Universidade de São Paulo, Ribeirão Preto, 2017.

Aprovado em:

Banca Examinadora

Prof. Dr.:

Instituição:

Julgamento:

Prof. Dr.:

Instituição:

Julgamento:

Prof. Dr.:

Instituição:

Julgamento: 


\section{AGRADECIMENTOS}

Em primeiro lugar, à Deus, que é a causa e o motivo maior de tudo isso.

Ao departamento de Bioquímica e Imunologia, sobretudo aos professores e funcionários do programa de pós-graduação em Bioquímica, que possibilitaram e contribuíram enormemente para a realização do meu mestrado.

Aos companheiros do laboratório do Prof. Sebastião, da psicobiologia da FFCL-RP, em especial ao Rodrigo Mazzei e Renata Pini, pela amizade, atenção e por sempre serem tão prestativos nos momentos em que precisei de ajuda.

Aos companheiros do LNNE, em especial o José Antônio, Victor, Polianna, Eduardo, Rui, Lívea e Ana, por todo o suporte que me deram ao longo da realização do meu projeto de mestrado.

A todos os companheiros do laboratório do Prof. Sebollela, em especial a Hanna, André, Niele e Silvana, por toda a contribuição (em todos os sentidos) que tiveram durante esta importante etapa da minha vida e, juntamente com os outros membros, pela amizade e companheirismo construído ao longo desses 2 anos. Novamente, muito obrigado!

Ao Artur Fernandes, também pela amizade e, em especial, por toda a paciência e ensinamentos que me passou durante este período, além da enorme contribuição para a realização do meu projeto de mestrado. Ao Prof. Norberto Garcia Cairasco, meu coorientador, por todo o suporte e contribuição essenciais para a realização do meu mestrado, bem como para a evolução da minha vida acadêmica. Ao Prof. Adriano Sebollela, meu orientador, pela oportunidade de fazer parte da sua equipe durante esses 2 anos de mestrado, por ser sempre tão atencioso e disposto a ajudar seus alunos nos momentos de necessidade, pela amizade e por todos os seus ensinamentos, que certamente levarei para a vida toda. Muito obrigado!

A toda a minha família, meu pilar de sustentação, que sempre me apoia e me dá forças para seguir em frente e superar as dificuldades que a vida impõe. Em especial, gostaria de agradecer à minha querida mãe, Elisângela, e também ao meu pai de criação, Luiz, que sempre estão comigo nos momentos bons e ruins. Agradeço também ao meu pai, Sinval, que mesmo longe fisicamente, sempre está presente na minha vida, contribuindo para o meu crescimento em todos os aspectos da vida. Muito obrigado, amo vocês! 


\section{SUMÁRIO}

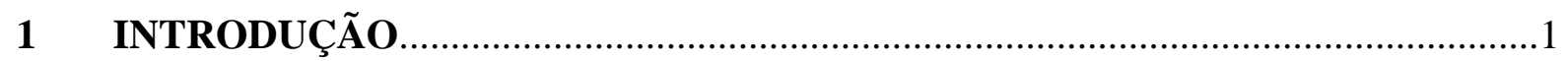

1.1 Doença de Alzheimer: visão geral.........................................................................

1.2 Aspectos celulares e moleculares característicos..........................................................4

1.3 Comorbidades relacionadas à doença de Alzheimer....................................................10

1.4 A cepa WAR como modelo de estudo das epilepsias e comorbidades..........................12

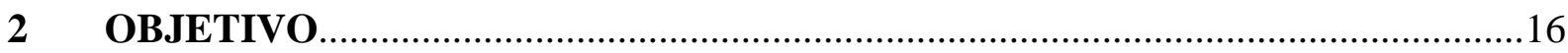

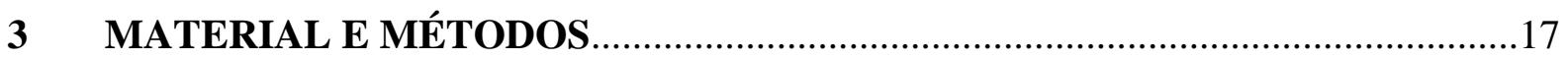

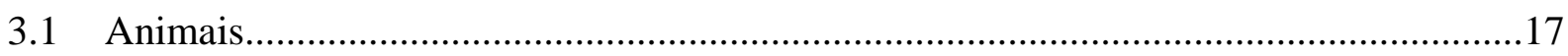

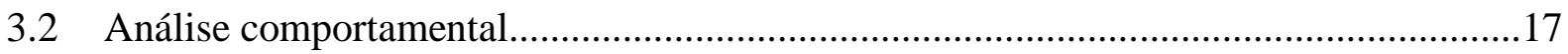

3.3 Análises bioquímicas de marcadores da doença de Alzheimer....................................19

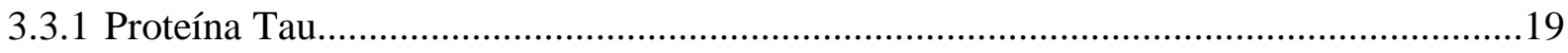

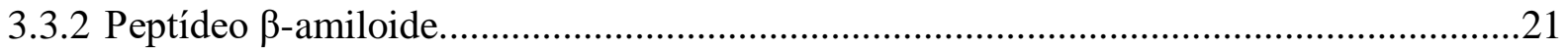

3.4 Análise da proteína Tau hiperfosforilada por imunoistoquímica..................................23

$4 \quad$ RESULTADOS

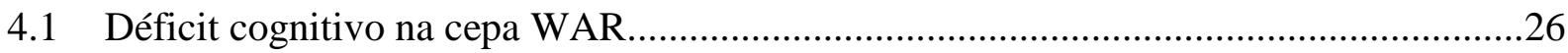

4.2 Análises dos biomarcadores da doença de Alzheimer................................................29

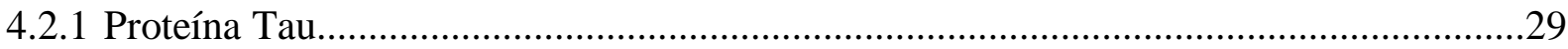

4.2.2 Análise da proteína Tau hiperfosforilada por imunoistoquímica...................................36

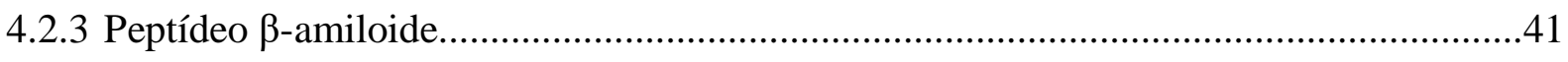

5 DISCUSSÃO

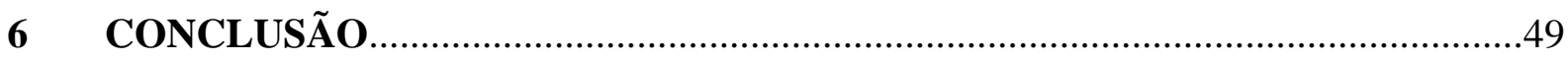

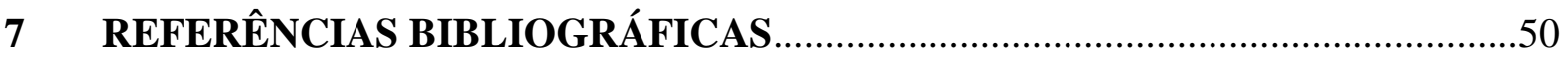

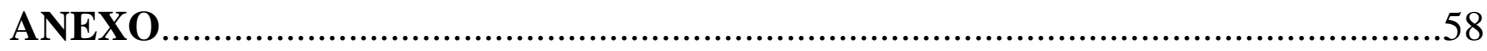




\section{LISTA DE FIGURAS}

Figura 1 Esquema do labirinto aquático de Morris .19

Figura 2 Déficit de memória espacial em ratos WAR de meia-idade (9 meses) avaliado pelo labirinto aquático de Morris (LAM)

Figura 3 Déficit de aprendizagem em ratos WAR de meia idade (12 meses) avaliado pelo LAM

Figura 4 Detecção de fragmento de degradação da proteína Tau em extratos de hipocampo dorsal e córtex pré-frontal submetidos ao armazenamento por congelamento.

Figura 5 Quantificação dos níveis da proteína Tau hiperfosforilada (pTau) e total em extratos de hipocampo dorsal de ratos adultos (12 meses).

Figura 6 Quantificação da proteína Tau hiperfosforilada (pTau) e total em extratos de córtex pré-frontal de ratos adultos (12 meses).

Figura 7 Padrão de imuno-marcação de pTau em secção de hipocampo de rato Wistar jovem (3-5 meses).

Figura 8 Acúmulo de proteína Tau hiperfosforilada (pTau) em regiões hipocampais específicas de animais WAR adultos (12 meses).

Figura 9 Detecção do peptídeo $\beta$-amiloide $(A \beta)$ em extratos de hipocampo dorsal de ratos adultos (12 meses) 


\section{RESUMO}

\section{VASCONCELOS, Israel Costa. Análise de biomarcadores e déficit comportamental associados à doença de Alzheimer em um modelo animal de predisposição genética à}

epilepsia. 2017. Dissertação (Mestrado em Bioquímica) - Faculdade de Medicina de Ribeirão

Preto, Universidade de São Paulo, Ribeirão Preto, 2017.

A doença de Alzheimer (DA) é uma patologia neuropsiquiátrica caracterizada por perda cognitiva, com marcante déficit de memória desde o estágio inicial, degeneração neuronal progressiva, e constitui a principal causa de demência no mundo. Além disso, a DA é frequentemente agravada pela ocorrência de comorbidades. Dados epidemiológicos apontam para uma importante associação clínica entre a DA e a epilepsia. A ausência de um modelo de estudo relevante, entretanto, tem impedido o avanço do entendimento dos mecanismos moleculares que subjazem essa comorbidade. A cepa Wistar Audiogenic Rat (WAR) tem sido amplamente utilizada como modelo animal para o estudo de epilepsia e, recentemente, déficits de memória foram relatados em animais desta cepa, o que suscitou a possibilidade de constituírem um modelo experimental para o estudo da comorbidade entre DA e epilepsia. No presente estudo, foi avaliado o desempenho de WAR adultos em diferentes idades no teste de memória do labirinto aquático de Morris (LAM). Realizaram-se ainda análises bioquímicas e de imunoistoquímica dos principais biomarcadores celulares da DA, o peptídeo beta-amiloide (A $\beta$ ) e a proteína Tau hiperfosforilada (pTau), no hipocampo e no córtex pré-frontal de WAR e Wistar de idades pareadas. No LAM, os WAR de 9 meses apresentaram déficit de aprendizagem e de retenção de memória (24 horas após o treinamento), quando comparados aos Wistar de idade pareada, enquanto que aos 12 meses, os WAR apresentaram apenas déficit de aprendizagem. Os animais WAR de 12 meses apresentaram também aumento significativo nos níveis de pTau e Tau total em extratos de hipocampo, quando comparados aos Wistar controles de mesma idade, o que não foi observado para os extratos de córtex pré-frontal. Os WAR também apresentaram elevação idade-dependente nos níveis e distribuição anormal de pTau em algumas sub-regiões hipocampais, como avaliado por imunoistoquímica. Não foi possível quantificar $A \beta$ endógeno por meio das estratégias utilizadas. Quando analisados em conjunto, os dados sugerem que os déficits de memória observados nos WAR podem ser reflexo da hiperfosforilação e consequente distribuição anormal da proteína neuronal Tau, por um mecanismo molecular a ser desvendado. Não foi possível, ainda, determinar se este mecanismo inclui aumento nos níveis de agregados de A $\beta$, como esperado em modelos de DA. Portanto, o emprego de cepa WAR como modelo experimental para o estudo dos fenômenos moleculares subjacentes à comorbidade entre epilepsia e doença de Alzheimer, embora promissor, ainda precisa ser melhor caracterizado.

Palavras-chave: cepa WAR, Alzheimer, epilepsia, comorbidades, Tau, hiperfosforilação, cognição. 


\begin{abstract}
VASCONCELOS, Israel Costa. Analysis of Alzheimer disease-associated biomarkers and behavioral deficits in an animal model of genetic predisposition to epilepsy. 2017.

Dissertation (Master's degree in Biochemistry) - Ribeirão Preto School of Medicine, University of São Paulo, Ribeirão Preto, 2017.
\end{abstract}

\begin{abstract}
Alzheimer disease (AD) is a neuropsychiatric disorder characterized by cognitive loss, marked memory deficit since the early stage, progressive neuronal degeneration, and it is the leading cause of dementia around the world. In addition, $\mathrm{AD}$ is often aggravated by the occurrence of comorbidities. Epidemiological data point to a clinical association between $\mathrm{AD}$ and epilepsy. The absence of a relevant model, however, has impaired the advance of the understanding about the molecular mechanisms that underlie this comorbidity. The Wistar Audiogenic Rat (WAR) strain has been widely used as an animal model to the study of epilepsy. Recently, memory deficits have been reported in WARs, which has raised the possibility that this strain may represent an experimental model to the study of comorbidity between AD and epilepsy. Here we evaluated the performance of WARs in the reference memory test Morris water maze (MWM) at different ages. Biochemical and immunohistochemical analyzes of the main AD biomarkers, beta-amyloid peptide $(A \beta)$ and hyperphosphorylated Tau protein (pTau), were also performed in the hippocampus and prefrontal cortex of age-matched WARs and Wistar controls. In the LAM, middle-aged (9 months) WARs presented learning and memory retention deficits (24 hours after training session) when compared to age-matched Wistar rats, whereas at 12 months, WARs presented only learning deficits. Adult WAR animals showed a significant increase in the levels of pTau and total Tau in hippocampal extracts, when compared to Wistar controls, which was not observed in prefrontal cortex extracts. WARs also showed higher levels and abnormal distribution of pTau in some hippocampal subregions, as assessed by immunohistochemistry. It was not possible to detect endogenous A $\beta$ by the strategies used. Taken together, these data suggest that memory deficits observed in WARs may be a consequence of hyperphosphorylation and consequent abnormal distribution of Tau triggered by a molecular mechanism yet to be identified. It has not yet been determined whether this mechanism includes increased levels of $A \beta$ aggregates, as expected in AD models. Therefore, the use of the WAR strain as an experimental model to the study of the molecular phenomena underlying the comorbidity between epilepsy and Alzheimer disease, although promising, still needs to be further characterized.
\end{abstract}

Keywords: WAR strain, Alzheimer disease, epilepsy, comorbidities, Tau, hyperphosphorylation, cognition. 


\section{INTRODUÇÃO}

\subsection{Doença de Alzheimer: visão geral}

A doença de Alzheimer (DA) é um transtorno neuropsiquiátrico crônico ainda sem cura, que se agrava de maneira progressiva até culminar na morte do seu portador. Na atualidade, constitui a causa mais comum de demência no mundo, contribuindo com 60 a $70 \%$ dos casos. Estima-se que, em 2015, 46,8 milhões de pessoas possuíam demência no mundo, e que este número tende a dobrar a cada 20 anos, alcançando 74,7 milhões em 2030 e 131,5 milhões em 2050 (WORLD HEALTH ORGANIZATION, 2015). Essa perspectiva representa um enorme impacto econômico, visto que a estimativa de custos com cuidados de saúde inerentes à demência, ao redor do mundo, é de US\$ 818 bilhões atualmente, podendo chegar a um trilhão de dólares em 2018 (PRINCE, 2015). No Brasil, estudos indicam que há uma prevalência média para o desenvolvimento de demência mais alta que a mundial, passando de 7,6\% para 7,9\% na população com 65 anos ou mais, entre 2010 e 2020, ou seja, 55.000 novos casos por ano (BURLÁ et al., 2013).

A DA foi descrita pela primeira vez em 1906 por um psiquiatra e neuropatologista alemão, Alois Alzheimer, de quem recebeu o nome, em um congresso de psiquiatria realizado na cidade de Munique. Na oportunidade, Alzheimer relatou o caso de uma paciente chamada Auguste Deter, a qual recebeu acompanhamento médico por 5 anos até o seu falecimento em 1906, aos 55 anos. Após este primeiro relato, outros casos semelhantes foram reportados na literatura médica nos anos seguintes, e só então, em 1910, a DA foi descrita pela primeira vez como condição autônoma, quando outro psiquiatra alemão, Emil Kraepelin, a incluiu na $8^{\mathrm{a}}$ edição do seu Manual de Psiquiatria, publicado em 15 de julho daquele ano (BERRIOS, 1990; HIPPIUS; NEUNDÖRFER, 2003). Durante muito tempo, considerou-se que a DA era um tipo raro de demência que ocorria no período pré-senil (ou seja, com surgimento dos sintomas antes dos 65 anos), e que os pacientes que apresentavam estes sintomas somente após a referida idade sofriam de demência senil comum. No entanto, estes conceitos foram gradualmente modificados com o passar dos anos, até o ponto em que se passou a adotar o termo "doença de Alzheimer" para descrever um quadro de características clínicas, neuropatológicas e comportamentais em comum, independente da faixa etária dos indivíduos que a sofrem (BERRIOS, 1990; BERCHTOLD; COTMAN, 1998). 
Historicamente, o envelhecimento sempre foi considerado o principal fator de risco para o desenvolvimento da DA. No entanto, com o avanço dos estudos epidemiológicos, vários outros possíveis fatores de risco têm sido apontados devido à demonstração de correlação destes com casos da doença, como por exemplo: baixo nível educacional, ausência de prática de atividades físicas durante a vida, traumas na cabeça, histórico de doença vascular, hábito de fumar, obesidade, diabetes, depressão, dentre outros (BLENNOW; DE LEON; ZETTERBERG, 2006; IKEDA e YAMADA, 2010). Apesar de muitos fatores de risco ambientais aumentarem a probabilidade para o seu desenvolvimento, atualmente existe a compreensão de que a DA possui um fundo genético significativo, considerado preponderante na etiopatogenia da doença, tanto para a forma esporádica quanto para a familiar. Basicamente, as duas formas diferem no que diz respeito à faixa etária na qual ocorre o surgimento dos sintomas, velocidade de progressão da doença e os genes envolvidos em cada caso (SELKOE, 2001; SERENIKI; VITAL, 2008).

A DA familiar, a forma mais rara e que corresponde a menos de $5 \%$ dos casos da doença, é transmitida por herança autossômica dominante, e os sintomas geralmente aparecem antes dos 65 anos, evoluindo de forma mais agressiva e levando o paciente à deterioração e morte rapidamente (BLENNOW; DE LEON; ZETTERBERG, 2006; CHAKRABARTI et al., 2015). Além das mutações no gene da proteína precursora amiloide (APP, do inglês amyloid precursor protein) localizado no cromossomo 21, primeiramente identificadas como causadoras desta forma da doença (GEORGE-HYSLOP et al., 1987), mutações nos genes de proteínas denominadas presenilina 1 (PSEN1) e presenilina 2 (PSEN2) - que constituem as subunidades catalíticas da enzima $\gamma$-secretase, uma das que participam da clivagem da APP e que geram os peptídeos beta-amiloide, cuja importância será discutida mais adiante - foram identificadas como as responsáveis pela maioria dos casos da doença familiar (IKEDA; YAMADA, 2010). A DA esporádica, por sua vez, não é transmitida por herança autossômica dominante, tendo os fatores ambientais e diferenças genéticas como principais fatores de risco. De acordo com a literatura, o fator de risco genético que mais se correlaciona com casos da doença é a herança do alelo $\varepsilon 4$ da apolipoproteína E (APOE), já que 40 a $80 \%$ dos pacientes possuem pelo menos um alelo $\varepsilon 4$ (MAHLEY; WEISGRABER; HUANG, 2006). Em heterozigotos, a presença deste alelo aumenta em 3 vezes o risco de desenvolvimento da doença, o qual sobe para 15 vezes quando em homozigose. Estima-se que cada cópia do alelo $\varepsilon 4$ antecipe o surgimento da doença em aproximadamente 10 anos (BLENNOW; DE LEON; ZETTERBERG, 2006). A DA esporádica é mais frequente na senilidade, com incidência 
próxima de $1 \%$ na população entre 60 e 70 anos, e cujo risco para o seu desenvolvimento é praticamente dobrado a cada 5 anos a partir dos 65 anos de idade. Na maioria dos casos, a progressão da DA esporádica é mais branda que a familiar, e a expectativa de vida média do paciente após o diagnóstico varia entre 3 e 9 anos (BEKRIS et al., 2010; ISIK, 2010).

O diagnóstico da DA geralmente é baseado na observação comportamental e histórico clínico do paciente e seus familiares, auxiliado por exames de imagem, como tomografia computadorizada e ressonância magnética. A sua confirmação só pode ser realizada após o óbito do paciente, através do estudo microscópico detalhado do seu tecido cerebral (BEKRIS et al., 2010; JOHNSON et al., 2012). Apesar da heterogeneidade da DA, no que diz respeito às características clínicas apresentadas pelos pacientes, existem sintomas em comum que estão presentes na maioria dos casos, e que permitem a divisão do curso da doença em 4 estágios, para fins de melhor entendimento, sendo eles: pré-demência, doença de Alzheimer branda (estágio inicial), doença de Alzheimer moderada (estágio intermediário) e doença de Alzheimer severa (estágio avançado) (FÖRSTL; KURZ, 1999).

O estágio de pré-demência é marcado pelo aparecimento de sintomas de difícil distinção em relação às mudanças que decorrem do processo normal de envelhecimento. Os pacientes podem apresentar deficiências cognitivas brandas, como perda de memória de curto prazo, déficits de atenção, de raciocínio ou memória semântica, além de sintomas neuropsiquiátricos como apatia (o mais persistente ao longo da evolução da doença), comportamento depressivo e dificuldade da percepção do próprio déficit de memória. Assim, os sintomas dessa fase, alternativamente chamada de déficit cognitivo leve, podem afetar a execução das tarefas mais complexas do cotidiano (LANDES et al., 2001; NYGÅRD, 2003; BÄCKMAN et al., 2004;).

No estágio inicial da DA, por sua vez, o paciente ainda possui autonomia suficiente para executar a grande maioria das tarefas do dia-a-dia. Entretanto, à medida que a doença progride, podem necessitar de assistência para as atividades de maior exigência cognitiva. Adicionados aos sintomas da fase de pré-demência estão a progressiva perda da memória (com ocorrência de lapsos, principalmente em relação às memórias recentes) e da capacidade de aprendizagem, além de maior dificuldade na organização do raciocínio. Numa pequena parcela dos pacientes, observa-se também dificuldades de linguagem (esquecimento de palavras familiares durante a formação de sentenças), da realização de funções executivas e da percepção (agnosia) ou coordenação durante execução de movimentos (apraxia) (CARLESIMO; OSCAR-BERMAN, 1992; FÖRSTL; KURZ, 1999;). 
O estágio intermediário da DA, em dado ponto, afeta a independência da pessoa, que passa a ser incapaz de realizar a maior parte das atividades do cotidiano. Nesta fase, a progressão da doença faz com que os déficits na linguagem falada e escrita se tornem mais evidentes, devido à dificuldade de recordação do vocabulário, o que leva a frequentes substituições incorretas de palavras (parafasia), além de prejuízos na capacidade de leitura (FÖRSTL; KURZ, 1999). Os problemas com a memória se agravam, o que pode levar a pessoa a parar de reconhecer familiares próximos, e também passam a ocorrer déficits na memória de longo prazo. Aumenta a prevalência das alterações comportamentais e neuropsiquiátricas, que passam a ser manifestadas por um estado geral de confusão, ausência e irritabilidade, além de episódios de manifestações emotivas, como choro, agressão involuntária ou resistência à prestação de cuidados de saúde (HAUPT; KURZ, 1993). Em alguns casos, pode ainda haver sintomas de alucinações (PERRY et al., 1990). Ocorre também a diminuição da coordenação para as atividades motoras mais complexas, aumentando o risco de queda, e as pessoas perdem a consciência das limitações que passam a ter por conta da doença (anosognosia) (FÖRSTL; KURZ, 1999).

Por fim, no estágio de DA severa, todas as funções cognitivas estão severamente comprometidas, incluindo a linguagem, a qual passa a ser reduzida a frases simples ou palavras isoladas, o que eventualmente leva à perda completa da capacidade de expressão verbal (FÖRSTL; KURZ, 1999). No entanto, muitas vezes a pessoa ainda consegue compreender e responder a sinais emocionais. O portador da doença passa a ser completamente dependente dos cuidadores, também por conta da extrema apatia e cansaço que são comuns a esta etapa, e ocorre a perda de massa muscular e mobilidade, ao ponto em que a pessoa se torna incapaz de sair da cama e alimentar a si própria. Nesta fase terminal, a causa direta da morte não é a DA em si, mas geralmente alguma doença ou infecção secundária, como pneumonia (FÖRSTL; KURZ, 1999; BRUNNSTRÖM; ENGLUND, 2009).

\subsection{Aspectos celulares e moleculares característicos}

Atualmente se sabe que as alterações microscópicas que ocorrem no cérebro dos pacientes com DA têm início antes mesmo do surgimento dos primeiros sinais de perda de memória e déficits cognitivos (SERRANO-POZO et al., 2011). Todos os sintomas descritos anteriormente se originam a partir do comprometimento estrutural e funcional das regiões cerebrais responsáveis pela coordenação e execução das funções cognitivas afetadas, que se dá pela disfunção sináptica e degeneração de múltiplas classes de neurônios, levando-os à morte, e provocando atrofia progressiva nestas regiões à medida que a doença evolui 
(SELKOE, 2001; WENK et al., 2003). Classicamente, as degenerações sináptica e neuronal observadas sempre foram atribuídas à presença de dois tipos de lesões neuropatológicas: as placas senis (compostas majoritariamente pela agregação dos peptídeos beta-amiloide) e os emaranhados neurofibrilares da proteína Tau, os quais serão discutidos em detalhes mais adiante. Essa atribuição se deu, inicialmente, por conta da realização de autópsias de pacientes com DA sintomática, onde foi constatada a presença das placas senis e emaranhados neurofibrilares em determinadas regiões cerebrais (BOURAS et al., 1994). Com a evolução das técnicas, estudos que utilizam exames de imagem in vivo demonstraram correlação entre a localização de deposição desses marcadores neuropatológicos - principalmente dos emaranhados neurofibrilares de Tau - e as áreas de estadiamento de Braak e Braak (1991), que correspondem às regiões cerebrais de maior prevalência de degeneração neurofibrilar na DA (SCHÖLL et al., 2016). Foi verificado que, nos estágios iniciais da doença, a região mais afetada geralmente corresponde ao lobo temporal, principalmente o hipocampo e córtex entorrinal - justificando o fato de os primeiros sintomas serem relativos à perda de memória de curto prazo, já que o hipocampo é a estrutura envolvida na formação de novas memórias episódicas e de referência espacial - com disseminação para outras áreas do sistema límbico, lobo parietal, giro do cíngulo, e chegando até algumas partes do lobo frontal, em estágios mais avançados (LEUNER; GOULD, 2010; SERRANO-POZO et al., 2011; SCHÖLL et al., 2016).

Do ponto de vista bioquímico, a DA pode ser considerada uma proteopatia, ou seja, doença caracterizada por anomalias no enovelamento de proteínas, que acarreta a perda das suas funções fisiológicas e/ou ganho de funções tóxicas (WALKER; LEVINE 3rd, 2002). Tanto as placas senis quanto os emaranhados neurofibrilares resultam do enovelamento inadequado de proteínas, através de um processo que ocorre de maneira gradual e contínua, e que, de maneira geral, tem início a partir da agregação de proteínas monoméricas em espécies mais complexas, os oligômeros de baixo peso molecular, seguido da formação de oligômeros de maior peso molecular, e gerando posteriormente estruturas com grau de complexidade cada vez mais alto, como as protofibrilas e fibrilas, fibras (ou filamentos) e, finalmente, os emaranhados e as placas (AHMED et al., 2010; PATTERSON et al., 2011; LASAGNAREEVES et al., 2012). Estes últimos são agregados densos e insolúveis nos ambientes em que se encontram, e acabam se depositando (IQBAL et al., 2005). Embora alguns idosos possam desenvolver placas senis e emaranhados neurofibrilares durante o processo normal de envelhecimento, o cérebro de pacientes com DA geralmente apresenta quantidade muito 
superior desses marcadores neuropatológicos, e mais concentrados em áreas específicas, como no lobo temporal (BOURAS et al., 1994).

O peptídeo beta-amiloide $(A \beta)$, principal componente das placas senis, se origina da clivagem enzimática da proteína transmembrana APP pela via amiloidogênica. Este processo ocorre primeiramente pela atividade da $\beta$-secretase, gerando dois fragmentos, um deles denominado APP solúvel (sAPP), que é liberado para o meio extracelular, e o outro denominado CTF $\beta$ (do inglês $C$-terminal fragment beta), que permanece ligado à membrana plasmática até a segunda enzima, a $\gamma$-secretase, realizar a sua clivagem, gerando o peptídeo A $\beta$ (MURPHY; LEVINE III, 2010; SERRANO-POZO et al., 2011). Como a $\gamma$-secretase realiza uma clivagem relativamente imprecisa, são geradas diferentes isoformas do peptídeo $\mathrm{A} \beta$, que variam entre si na região $\mathrm{C}$-terminal e na quantidade de resíduos de aminoácidos que os compõem, de 39 a 43 resíduos. A isoforma mais abundante (de 80 a 90\%) é a que termina na posição 40 (A $\beta-40)$, seguida pela que termina na posição 42 (A $\beta-42$, de 5 a 10\%), sendo esta última a mais hidrofóbica das espécies e, portanto, a que apresenta maior capacidade de agregação (MURPHY; LEVINE III, 2010; SERRANO-POZO et al., 2011).

Durante muito tempo, o papel dos peptídeos $\mathrm{A} \beta$ na etiologia da DA foi creditado à sua capacidade de formação e deposição de agregados fibrilares e placas senis no meio extracelular, sendo estas as formas consideradas tóxicas para os neurônios. No entanto, estudos realizados no fim da década de 90 e início dos anos 2000, até os dias atuais, vêm demonstrando que as espécies solúveis resultantes de um estágio de agregação mais precoce dos peptídeos $A \beta$, os oligômeros, apresentam toxicidade muito mais elevada para células de diversos tipos, desencadeando um grupo diferente de eventos tóxicos em comparação aos agregados insolúveis (LAMBERT et al., 1998; DESHPANDE et al. , 2006). Os oligômeros se formam majoritariamente a partir da agregação de monômeros $A \beta-42$ - graças à maior hidrofobicidade proporcionada pela sua porção C-terminal - e, de forma menos frequente, pela agregação de A $\beta-40$ (BITAN et al., 2003; KOFFIE et al., 2009). De fato, já foi demonstrada a existência de correlação entre o aumento na proporção de A $\beta-42 / A-\beta 40$ no cérebro de portadores da DA e o surgimento dos primeiros sintomas na DA familiar (DUERING et al., 2005). Dentre o vasto espectro de espécies oligoméricas de A $\beta$, existem algumas mais prevalentes em relação à abundância e potencial de neurotoxicidade, como por exemplo os dímeros SDS-resistentes, que já foram isolados de amostras de cérebro e líquido cefalorraquidiano de pacientes com DA, e se mostraram capazes de perturbar a plasticidade sináptica de neurônios hipocampais em ratos adultos, como observado por estudos 
eletrofisiológicos e testes de memória em modelo animal (KLYBIN et al., 2008; SHANKAR et al., 2008). Resultados semelhantes foram obtidos para trímeros e tetrâmeros gerados a partir da expressão de A $\beta$ humano em cultura de células (TOWNSEND et al., 2006), reforçando a teoria de que as espécies oligoméricas difusíveis de baixo peso molecular são as responsáveis por desencadear fenômenos de disfunção sináptica, e que provavelmente possuem papel importante na gênese de alguns dos eventos que subjazem o início da DA. Por outro lado, outras vertentes defendem que os oligômeros de alto peso molecular e maior complexidade, como os dodecâmeros, são as espécies tóxicas que estão primariamente envolvidas na etiologia da DA (GONG et al., 2003; LESNÉ et al., 2006; BERNSTEIN et al., 2009; ECONOMOU et al., 2016). Interessantemente, em um estudo mais recente, foi mostrado que oligômeros de baixo e alto peso molecular apresentam atividade amnésica em camundongos, e que respondem de forma diferente ao fármaco memantina, usado na clínica contra a DA (FIGUEIREDO et al., 2013). Fato é que, com a consolidação da hipótese que propõe os oligômeros como principais espécies causadoras da disfunção sináptica observada em pacientes com DA, o papel dos agregados mais complexos - notadamente as fibras e placas senis - deixou de ser primariamente o de agentes neurotóxicos diretos, mas o de reservatórios de oligômeros, já que foi demonstrada fraca correlação entre a densidade de placas senis e o grau de severidade do déficit de memória ou disfunção neuronal, apesar de ainda existirem divergências neste aspecto (SELKOE, 2001; NICOLL, 2005; BUSCHE et al., 2008; KOFFIE et al., 2009; GASPAR et al., 2010; KAYED; LASAGNA-REEVES, 2013).

$\mathrm{O}$ acúmulo extracelular e intracelular da proteína $\beta$-amiloide no cérebro inicia uma cascata de eventos que culmina em neurodegeneração (KOWALSKA, 2003). Dentre os principais eventos, estão: ligação de agregados de $\mathrm{A} \beta$ à receptores extracelulares, gerando redução na densidade de espinhas dendríticas (LACOR et al., 2007); resposta inflamatória por ativação microglial e astrocítica, promovida pela presença de componentes do sistema complemento nas placas senis, o que leva à produção de citocinas pró-inflamatórias e aumento nos níveis de radicais livres (EIKELENBOOM et al., 1988; EMMERLING et al., 2000); alterações metabólicas nas células, provocadas pela presença dos agregados intracelulares de $\mathrm{A} \beta$, como prejuízos nos mecanismos de degradação de proteínas, no transporte axonal e autofagia (LI et al., 2007; LAFERLA; GREEN; ODDO, 2007); alterações no transporte e nos níveis intracelulares de íons metálicos e $\mathrm{Ca}^{2+}$, que pode ter diversos efeitos secundários, como a modulação no grau de excitabilidade da membrana plasmática, regulação da atividade de enzimas como as quinases e fosfatases, expressão gênica, função 
mitocondrial, formação de espécies reativas de oxigênio e nitrogênio, além de indução de processos de morte celular do tipo apoptose ou necrose (SAYRE et al., 2004; SUPNET; BEZPROZVANNY, 2010; SEBOLLELA et al., 2012). Um dos eventos dessa cascata de patogênese da DA, a alteração na regulação de enzimas quinases e fosfatases, leva a mudanças nos níveis de fosforilação de diversas proteínas no interior dos neurônios, dentre elas, a proteína Tau, o outro principal biomarcador celular da doença.

A Tau é uma proteína da grande família de proteínas associadas a microtúbulos, as MAPs (do inglês microtubule-associated proteins), sendo codificada por um único gene localizado no cromossomo 17, o MAPT (IQBAL et al., 2005). Devido à ocorrência de fenômenos de splicing alternativo no seu pré-RNA mensageiro (envolvendo os éxons 2, 3 e 10), foram identificadas até o momento 6 isoformas dessa proteína em humanos, que diferem entre si no que diz respeito a conter zero $(0 \mathrm{~N})$, um $(1 \mathrm{~N})$ ou dois $(2 \mathrm{~N})$ insertos de 29 aminoácidos cada na porção amino-terminal, e à presença de três (3R) ou quatro (4R) repetições de domínios de ligação a microtúbulos na porção carboxi-terminal (GOEDERT et al., 1989; IQBAL; LIU; GONG, 2016). No cérebro, a Tau é encontrada principalmente em neurônios, mas também está presente em baixos níveis nas células da glia, além de estudos mais recentes já terem indicado que é possível detectá-la no meio extracelular (WANG; MANDELKOW, 2015). Em condições normais, trata-se de uma proteína solúvel e com baixo potencial de agregação, sendo que a principal função da Tau consiste em participar da montagem dos microtúbulos que constituem o citoesqueleto celular, através da promoção da interação das proteínas que compõem suas subunidades, as tubulinas, além de estabilizar sua estrutura (IQBAL et al., 2005; CONDE; CÁCERES, 2009). Também já foi reportado que a Tau está envolvida em vias de sinalização celular relacionadas à neurotransmissão, como a via Fyn (IQBAL; LIU; GONG, 2016).

A função de promoção da montagem dos microtúbulos mediada pela Tau é regulada pelo seu grau de fosforilação. Os níveis ótimos para o funcionamento normal da Tau no cérebro variam entre 2 a $3 \mathrm{mols}$ de fosfato/mol da proteína, e a ocorrência de hiperfosforilação, sobretudo em alguns resíduos específicos da cadeia polipeptídica, inibe sua capacidade de ligação aos microtúbulos, bem como de promover a montagem e estabilização destes (IQBAL et al., 2005). Na doença de Alzheimer, Tau sofre hiperfosforilação e acaba adquirindo uma conformação tridimensional que a torna mais propensa a se agregar com outras proteínas (principalmente com outros monômeros de Tau), formando estruturas mais complexas denominadas filamentos helicoidais emparelhados (PHF, do ingles paired helical 
filament), fitas retorcidas e filamentos retos que, por sua vez, acabam se acumulando e dando origem à espécie insolúvel intraneuronal considerada um dos principais marcadores neuropatológicos da DA, os emaranhados neurofibrilares (SELKOE, 2001; IQBAL et al., 2005). Com isto, perde-se a estabilidade da interação entre as tubulinas e os microtúbulos acabam sendo desmontados, fazendo com que as funções celulares dependentes deste tipo de estrutura deixem de ser executadas, notadamente o transporte axoplasmático de organelas, vesículas sinápticas, lipídios, proteínas e outros cargos importantes (IQBAL et al., 2005). Desta forma, gera-se uma grande perturbação na homeostase dos neurônios, que tem por consequência a sua disfunção, degeneração e morte, levando à demência.

O grau de fosforilação de uma fosfoproteína depende do balanço entre as atividades de proteínas quinases e fosfatases. Na DA, a Tau é fosforilada em mais de 30 resíduos de serina/treonina pelo fato de ser substrato de várias proteínas quinases, dentre as quais é possível citar a glicogênio sintase quinase-3 beta (GSK-3 $\beta$ ), a proteína quinase- 5 dependente de ciclina (cdk5) e a proteína quinase A (PKA), que são as mais implicadas em hiperfosforilação anômala de Tau (SINGH et al., 1994; HANGER et al., 1998; IQBAL et al., 2005; TIAN et al., 2009). Existem diversos sítios na cadeia polipeptídica de Tau que são hiperfosforilados por essas e outras proteínas quinase, inclusive, um mesmo sítio pode ser fosforilado por mais de uma quinase (ANDERTON et al., 2001). A hiperfosforilação de alguns sítios específicos, como o resíduo de serina localizado na posição 396 da cadeia, leva a mudanças conformacionais da Tau, capazes de provocar uma redução na sua capacidade de ligação aos microtúbulos e favorecendo sua agregação com outras moléculas de Tau por interação hidrofóbica (BRAMBLETT et al., 1993; IQBAL et al., 2005; JEGANATHAN et al., 2008). Assim, as moléculas normais de Tau são convertidas a espécies tóxicas.

Vários trabalhos realizados já indicaram esta correlação entre a presença de emaranhados neurofibrilares - compostos por Tau hiperfosforilada - e a expressão do fenótipo de degeneração neuronal e/ou déficits cognitivos típicos da DA e de outras doenças neurodegenerativas, através da utilização de diversas estratégias, como por exemplo: emprego da expressão de Tau humana, tanto do tipo selvagem quanto mutada, em animais transgênicos (ANDORFER et al., 2003; ZILKA et al., 2006; DICKSTEIN et al., 2010), expressão em modelos de cultura de células (BANDYOPADHYAY et al., 2007; WU; DICKSTEIN; DUFF, 2013), estudos de imagem em pacientes com demência tipo DA (CHIEN et al., 2013; SCHÖLL et al., 2016), além dos clássicos estudos neuropatológicos em cérebros provenientes 
de autópsias de pessoas com DA sintomático, como o relatado pelo próprio Dr. Alois Alzheimer em 1906.

\subsection{Comorbidades relacionadas à doença de Alzheimer}

A DA é considerada uma condição complexa por si só, e que leva o seu portador a uma piora gradativa da qualidade de vida. Frequentemente, este paradigma se torna ainda mais complexo e prejudicial para o paciente pela ocorrência de comorbidades associadas à DA, o que geralmente leva ao aumento da mortalidade. O termo comorbidade define uma condição em que duas ou mais patologias ocorrem simultaneamente, podendo dividir os mesmos mecanismos moleculares, genéticos e/ou anatômicos (GAITATZIS et al., 2004). Dentre os diversos tipos de comorbidades descritos, as neuropatológicas e psiquiátricas são comuns em portadores da DA. Já está bem descrita, por exemplo, a forte correlação entre a Síndrome de Down e a DA, visto que os pacientes portadores desta síndrome frequentemente apresentam alta carga de placas senis de $A \beta$. Hoje sabe-se que essa alta produção de $A \beta$, que culmina na formação de agregados, é devida a trissomia do cromossomo 21 , onde está localizado o gene da APP (HEAD et al., 2012). Outros transtornos neuropsiquiátricos também já descritos como comorbidades com a DA incluem o transtorno bipolar (KESSING; ANDERSEN, 2004), esquizofrenia (DOUAUD et al., 2014), e o mais prevalente de todos, a depressão (DINIZ et al., 2013; GARCEZ et al., 2015). Mais recentemente, despertou-se um crescente interesse em estudar a comorbidade entre epilepsia e a DA, pelo fato de alguns trabalhos já demonstrarem incidência significativamente maior (de 6 a 10 vezes) de crises epiléticas em pacientes com DA do que em pacientes controle sem demência, sobretudo os que apresentam a forma de início precoce (HAUSER et al., 1986; ROMANELLI et al., 1990; AMATNIEK et al., 2006). Além disso, também já foi constatado, em um estudo do tipo casocontrole, que a DA realmente constitui um fator de risco significativo para o desenvolvimento de ataques epiléticos (HESDORFFER et al., 1996). Embora os estudos venham comprovando cada vez mais a consistência da conexão entre a DA e epilepsia, a relação de causa e efeito entre estas patologias ainda é bastante discutida. Dados epidemiológicos apontam que o início das crises epiléticas acontece, em média, após 3,3 anos do início da DA, apesar de existir uma pequena porcentagem de pacientes $(3,4 \%)$ que as desenvolve logo no início do declínio cognitivo (HESDORFFER et al., 1996; LOZSADI; LARNER, 2006).

A DA e a epilepsia possuem muitas características fisiopatológicas convergentes, incluindo atrofia do lobo temporal (no caso de epilepsias de lobo temporal), morte neuronal, gliose, alterações neuríticas e inflamação (COOK et al., 1992; BUCKMASTER e DUDEK, 
1997; YAN et al., 2012). De fato, a existência de características comuns a ambos os distúrbios já tem sido relatada há muito tempo, visto que, desde 1892 já havia sido descrita a presença de placas senis em cérebro humano epilético (MARINESCO, 1892; YAN et al., 2012), portanto, antes mesmo da primeira descrição de caso clínico de DA pelo Dr. Alzheimer. Posteriormente, também foi observada a ocorrência de tauopatia em cérebro epilético humano (HAUSER et al., 1986; NAGAISHI et al., 2011; TAI et al., 2016). Somado a isto, estudos neuropsicológicos e de neuroimagem funcional revelaram que pacientes com epilepsia podem apresentar alguns distúrbios cognitivos característicos da DA, como déficit de atenção, problemas de memória, linguagem e execução de tarefas, em diferentes graus, dependendo do tipo de epilepsia (VLOOSWIJK et al., 2010).

Apesar destes indícios de convergência e sobreposição de fenômenos fisiopatológicos entre DA e epilepsia, ainda pouco se conhece sobre os mecanismos moleculares e celulares que subjazem sua etiopatogenia. $O$ desenvolvimento de modelos animais para as duas patologias tem permitido o avanço na compreensão de alguns aspectos. Um exemplo foi demonstrado no estudo feito por Palop e colaboradores (2007), onde camundongos transgênicos modificados geneticamente para superexpressar APP humana com uma das mutações presentes na doença de Alzheimer familiar - e que apresentavam, portanto, alterações típicas da DA relacionadas ao acúmulo de agregados de $\mathrm{A} \beta$ no cérebro - também apresentavam indícios de aumento aberrante da atividade excitatória de redes neuronais no hipocampo, típico de pacientes com epilepsia e de modelos animais utilizados para o estudo desta patologia. Foi observado que estes eventos desencadearam uma série de alterações anatômicas e bioquímicas que resultaram em aumento na inibição desta circuitaria, provavelmente devido a um mecanismo compensatório de proteção. Assim, a conclusão dos autores foi que tanto a atividade excitatória neuronal aberrante, quanto os mecanismos compensatórios de inibição, podem limitar a capacidade de plasticidade sináptica, além de contribuir para as disfunções das redes neuronais relacionadas à DA. Outro estudo publicado no ano seguinte (2008), realizado por Busche e colaboradores, reforçou a ideia da conjunção de eventos que acarretam a hiperatividade neuronal e mecanismos compensatórios de inibição, em neurônios corticais de camundongos transgênicos de 6-8 meses que expressavam APP e presenilina humanas mutantes, um modelo animal de DA familiar. Foi observado nestes animais uma redução na quantidade de neurônios que apresentavam frequência normal de disparos de potencial de ação, em detrimento ao aumento tanto na quantidade de neurônios hiperexcitados, sobretudo em volta das regiões de acúmulo de placas de A $\beta$, quanto de 
neurônios com atividade inibida (espalhados de maneira mais uniforme ao longo do córtex), em comparação aos camundongos controles de idade pareada. Os camundongos transgênicos também apresentaram déficits de memória. Neste estudo, foi verificado ainda que as alterações neuronais e comportamentais observadas eram dependentes da presença de placas de $A \beta$, pois estes mesmos animais transgênicos, aos 2 meses de idade, ainda isentos de placas, apresentaram atividade cortical e desempenho cognitivo normais. Outro exemplo de contribuição de modelos animais para o entendimento de aspectos relacionados à comorbidade entre DA e epilepsia foi a elucidação, ao menos parcial, do papel da via de sinalização de mTOR (do inglês mammalian target of rapamycin) como elo de ligação entre as duas doenças. Já foi demonstrado que perturbações nesta via, que regula múltiplas funções celulares, podem contribuir tanto para a epileptogênese - através da síntese de proteínas, crescimento, proliferação e migração celular, que leva ao brotamento de fibras musgosas no hipocampo, observado na fase crônica da epilepsia - quanto para eventos que desencadeiam a DA, como o aumento dos depósitos de A - mTOR estimula a tradução do mRNA proveniente de genes produtores de proteínas sinápticas dos dendritos, como o da APP, logo, quando superestimulada, esta via leva ao aumento de expressão de APP e maior produção do peptídeo A $\beta$ (BUCKMASTER; INGRAM; WEN, 2009; SHARMA et al., 2010). No entanto, um dos problemas inerentes a estes estudos, e que dificulta a continuidade da evolução do conhecimento na área, é que os modelos experimentais utilizados apresentam limitações relevantes. Os modelos animais normalmente utilizados para o estudo da DA são camundongos transgênicos, modificados geneticamente para expressar formas selvagens ou mutadas de proteínas humanas envolvidas na geração de A , APP e presenilina. Esses animais, além de apresentarem desenvolvimento muito agudo da doença, carregam complicações e consequências relativas à manipulação genética, o que dificulta a translacionalidade dos resultados obtidos para a realidade da doença em humanos. Os modelos geralmente utilizados para estudo da epilepsia também apresentam limitações importantes, pois envolvem o uso de fatores convulsivantes químicos ou elétricos para indução de crises em animais normais. Portanto, fica cada vez mais evidente a necessidade de se estabelecer um modelo experimental animal capaz de mimetizar as características destas doenças, com redução das manipulações genéticas ou farmacológicas, a fim de reduzir a influência de variáveis externas no fenótipo observado.

\subsection{A cepa de ratos WAR como modelo de estudo das epilepsias e comorbidades}


A cepa de animais Wistar Audiogenic Rats (WAR) surgiu como alternativa de modelo experimental para o estudo de epilepsia. Esta cepa foi gerada pela seleção de animais da linhagem Wistar que apresentavam predisposição a desenvolver crises epilépticas quando expostos a um estímulo sonoro de alta intensidade, e subsequentes cruzamentos endogâmicos entre estes animais, gerando filhotes cada vez mais susceptíveis às crises (GARCIACAIRASCO; SABBATINI, 1983; DORETTO et al., 2003). Com a progressão das gerações, os animais desta cepa passaram a apresentar um consistente padrão genético, refletido em homogeneidade de fenótipo para algumas características que habilitaram a cepa WAR a constituir modelo experimental bem estabelecido para o estudo de 2 tipos de epilepsia: (1) epilepsia generalizada do tipo tônico-clônica, em que o disparo da crise acontece em regiões do mesencéfalo durante o primeiro estímulo sonoro, e envolve grande parte do sistema nervoso central (GARCIA-CAIRASCO; TERRA; DORETTO, 1993); e (2) epilepsia de lobo temporal, na qual ocorre a disseminação de atividade epilética das estruturas mesencefálicas para as estruturas límbicas, durante a progressão das crises, devido a repetição do estímulo sonoro, e os animais passam a apresentar sintomas de crises parciais complexas que caracterizam a epilepsia de lobo temporal (GALVIS-ALONSO; OLIVEIRA; GARCIACAIRASCO, 2004). Os animais WAR apresentam latência reduzida para o início das crises audiogênicas, e estas acontecem de maneira mais grave em comparação aos animais Wistar controle, como demonstrado por análises comportamentais e registros eletroencefalográficos do córtex, hipocampo e amígdala (MARESCAUX et al., 1987; GARCIA-CAIRASCO et al., 1996.a; ROMCY-PEREIRA; GARCIA-CAIRASCO, 2003). A latência reduzida para o início das crises pode ser um reflexo de excitabilidade aumentada dos neurônios que fazem parte das circuitarias envolvidas na gênese da atividade epilética, como foi observado em axônios presentes na via Schaffer-CA1 hipocampal de ratos WAR de 2 meses de idade, através de estudos de eletrofisiologia (CUNHA et al., 2015). Apesar de os estímulos sonoros repetidos não promoverem brotamento anormal de fibras musgosas e morte neuronal no hipocampo de ratos WAR, diferente do que ocorre em pacientes e outros modelos animais de epilepsia, foi verificado por métodos histoquímicos que estes estímulos foram capazes de gerar morte neuronal significativa na região do núcleo rostral-lateral da amígdala de WARs, bem como reorganização de terminações sinápticas glutamatérgicas na amígdala e nos córtices piriforme e perirrinal, quando comparados aos ratos Wistar, indicando a ocorrência de algum fenômeno vigente nestas regiões, e que provavelmente constitui um importante substrato para o desenvolvimento de uma rede límbica de atividade epilética neste modelo (GARCIACAIRASCO et al., 1996.b; GALVIS-ALONSO; OLIVEIRA; GARCIA-CAIRASCO, 2004). 
Além da maior susceptibilidade às crises audiogênicas, estes animais apresentam uma série de outras alterações que podem se refletir em comorbidades. Dentre as alterações observadas em diversos estudos, é possível citar: pressão arterial e frequência cardíaca aumentada em animais WAR adultos, mesmo na ausência de estímulos de qualquer natureza, indicando perturbações inatas no controle do sistema circulatório (FAZAN et al., 2011); reduzida ventilação de repouso e resposta ventilatória a condições de hipercapnia e hipóxia, além de redução na quantidade de neurônios quimiosensitivos da coluna respiratória ventral e na neurotransmissão serotonérgica nesta região, que implica em déficit respiratório e torna a cepa WAR um modelo adequado para o estudo de riscos respiratórios associados à epilepsia (GRANJEIRO et al., 2016; TOTOLA et al., 2016); embora apresentem uma curva de crescimento diminuída em comparação aos ratos Wistar controles, possuem hiperplasia da glândula adrenal, com menor liberação basal de hormônio adenocorticotrófico e corticosterona, indicando distúrbios neuroendócrinos (UMEOKA et al., 2011); alteração na expressão de genes da família EGR (do inglês early growth response genes) principalmente dos genes Egr 1, Egr 2 e Egr 3, responsáveis pela expressão de fatores de crescimento envolvidos em processos como crescimento celular, apoptose, potenciação de longo prazo, mielinização e sinalização corticosteroide, em neurônios da região do colículo inferior, após submissão ao estímulo sonoro de alta intensidade (LÓPEZ-LÓPEZ et al., 2016).

A associação de comorbidades neuropsiquiátricas à susceptibilidade inata da cepa WAR às crises epiléticas também tem sido descrita. Quando animais WAR foram submetidos aos testes de labirinto em cruz elevado e campo aberto, apresentaram um comportamento de ansiedade maior que os animais Wistar controles, como demonstrado pela diminuição da exploração nos braços abertos do labirinto e pela reduzida distância explorada no campo aberto (GARCIA-CAIRASCO et al., 1998). Outro trabalho comparou os níveis de comportamento compulsivo da cepa WAR a um dos modelos utilizados para o estudo deste parâmetro, que consiste na injeção de ocitocina na amígdala central de ratos Wistar, provocando o que é chamado de hypergrooming (autolimpeza exacerbada). Nesse caso, verificou-se que os WARs injetados com salina (veículo) apresentaram hypergrooming equivalente aos animais injetados com ocitocina, demonstrando que os animais WAR apresentam comportamento compulsivo inato (MARRONI et al., 2009). Além destas comorbidades mencionadas, recentemente, déficits de memória foram relatados em animais da cepa. Em 2015, Cunha e colaboradores demonstraram que, além dos WARs apresentarem um desenvolvimento mais lento de potenciação de longo prazo (LTP, do inglês long term 
potentiation) - um dos fenômenos que contribuem para a plasticidade sináptica, envolvido nos mecanismos celulares que constituem a base da aprendizagem e memória - em neurônios hipocampais, estes animais também apresentaram déficit endógeno de retenção de memória espacial e de referência, aos 2 meses de idade, como avaliado pelo teste labirinto aquático de Morris, após terem sido submetidos a uma etapa prévia de treinamento, quando comparados aos ratos Wistar controles de idade pareada, igualmente treinados. Estes dados, juntamente com outros dados ainda não publicados do nosso grupo de pesquisa, usando o teste de reconhecimento de objetos, que também indicou déficit de memória em animais WAR de meia-idade (7 meses), levantaram a possibilidade da cepa WAR constituir um modelo experimental adequado para o estudo da comorbidade entre a doença de Alzheimer e epilepsia. 


\section{OBJETIVO}

Avaliar o desempenho de animais da cepa WAR, em diferentes idades, no teste de memória de referência denominado labirinto aquático de Morris, bem como analisar os principais biomarcadores da doença de Alzheimer nestes animais adultos, com a finalidade de caracterizar a cepa como um modelo experimental adequado para o estudo dos mecanismos moleculares que subjazem a comorbidade entre a doença de Alzheimer e a epilepsia. 


\section{MATERIAL E MÉTODOS}

\subsection{Animais:}

Todos os procedimentos experimentais realizados com os animais foram aprovados pela Comissão de Ética no Uso de Animais (CEUA-FMRP), sob o protocolo 017/2014-1. Em todos os experimentos foram utilizados ratos da espécie Rattus norvegicus pertencentes às linhagens Wistar (controle) ou Wistar Audiogenic Rats (WAR). Os ratos da linhagem Wistar foram obtidos do biotério central da USP de Ribeirão Preto, e foram mantidos em ambiente ventilado com filtração do ar, temperatura por volta de $25^{\circ} \mathrm{C}$, fotoperíodo de doze horas (7:00h-19:00h), e água e alimentação ad libitum. Os animais da cepa WAR foram obtidos do biotério do Departamento de Fisiologia da Faculdade de Medicina da USP de Ribeirão Preto, e foram mantidos nas mesmas condições.

\subsection{Análise comportamental:}

A aprendizagem e a memória espacial dos animais foram avaliadas pelo teste do labirinto aquático de Morris (LAM), com base no descrito em Morris (1981). O teste consiste em submeter os animais a um labirinto aquático (Fig. 1), e o protocolo experimental é dividido em duas fases: a fase de aprendizagem e o teste de retenção de memória. Na fase de aprendizagem (primeira fase), que compreendeu os dois primeiros dias do teste, os animais foram submetidos a 12 tentativas de encontro da plataforma por dia, totalizando 24 tentativas, e a memória foi verificada nos testes de retenção de memória, realizados 24 horas e 7 dias após a fase de aprendizagem. Todos os animais foram testados aos 9 e também aos 12 meses de idade. No protocolo utilizado, inicialmente o animal foi posicionado de costas para o centro do tanque, em um dos quadrantes (exceto aquele onde permaneceu a plataforma) e foi permitido a ele nadar em busca da plataforma de fuga por um período de até 60 segundos. Nas ocasiões em que o animal não conseguiu alcançar a plataforma dentro do tempo estabelecido, ele foi guiado pelo experimentador até a plataforma. Entre as tentativas, cada animal permaneceu sobre a plataforma por um intervalo de 35 segundos. As posições de saída para cada tentativa foram determinadas aleatoriamente, em proporções iguais, e a plataforma permaneceu na mesma localização durante todo o experimento. Depois da última tentativa do segundo dia de testes (T24), a plataforma foi removida e o animal colocado no quadrante 
diagonalmente oposto àquele que continha a plataforma, e foi imposto um período de 60 segundos de natação (probe trial). Foi registrado o tempo despendido e analisado o percentual de permanência em cada quadrante. A probe trial (25 tentativa), que consiste em uma tentativa de extinção (já que na ausência da plataforma o comportamento do animal não foi reforçado), possibilitou analisar a precisão de navegação do animal em busca da plataforma, bem como a efetivação do aprendizado da tarefa. Após 24 horas (T26) e 7 dias (T27) desta fase de aprendizagem, cada animal foi novamente testado em uma única tentativa (teste de retenção de memória). Os animais foram colocados no labirinto aquático, no quadrante diagonalmente oposto àquele em que estava fixada a plataforma. Nestas tentativas, cada animal teve 180 segundos para encontrar a plataforma submersa, que estava na mesma localização em que permaneceu durante todo o experimento. A análise dos dados foi realizada com o programa Ethovision versão 3.0. O teste estatístico utilizado foi o ANOVA de duas vias, considerando-se $\mathrm{p}<0,05$ como significância estatística, para a verificação de possíveis diferenças no desempenho dos grupos nos parâmetros latência de fuga, distância navegada e velocidade de natação. Nessa análise, as 24 tentativas da fase de aprendizagem foram agrupadas em 6 blocos de 4 tentativas cada, enquanto que no teste de retenção de memória, o desempenho de um grupo nas tentativas realizadas após 24 horas e 7 dias $\left(26^{\mathrm{a}}\right.$ e $27^{\mathrm{a}}$ tentativas, respectivamente) da fase de aprendizagem foi comparado ao seu próprio desempenho na última tentativa desta mesma fase (24 tentativa). Desta forma, foi avaliado individualmente para cada parâmetro: se o desempenho de um grupo foi, de maneira geral, diferente em relação ao desempenho do outro grupo, nas tentativas em questão (efeito de grupos); se o treinamento surtiu algum efeito no desempenho dos animais ao longo da progressão do teste, nas tentativas em questão (efeito de tentativas); se foi possível determinar em qual ou quais tentativas houve a diferença de desempenho - de um grupo em relação ao outro na mesma tentativa, ou de um grupo comparado consigo mesmo entre diferentes tentativas - informação esta que é fornecida pelo teste Post Hoc de Newman-Keuls (efeito de interação entre os fatores grupos $\mathrm{x}$ tentativas). 


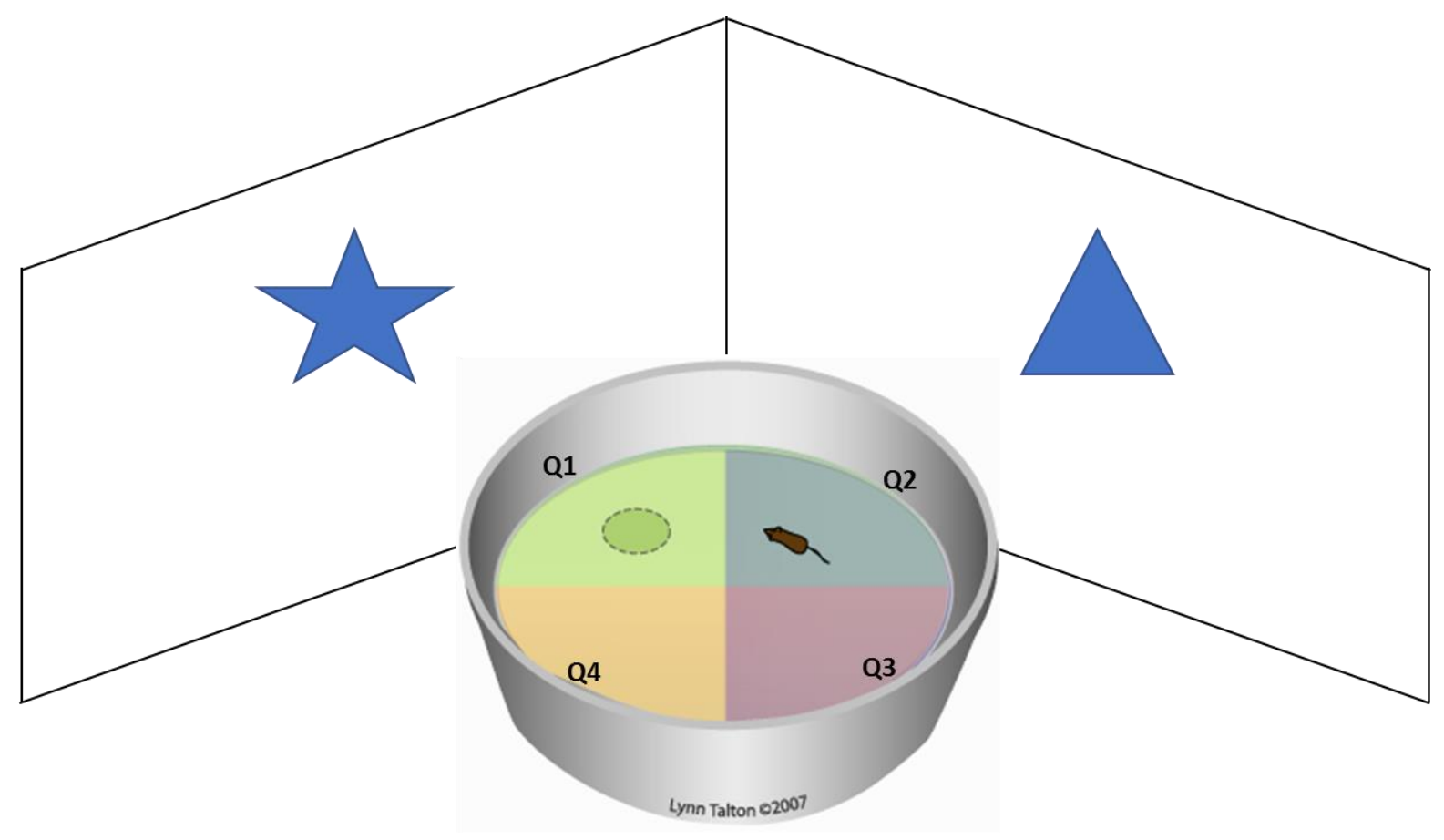

Figura 1 - Esquema do labirinto aquático de Morris. O labirinto aquático é constituído por um tanque circular de fibra de vidro de cor preta, com $150 \mathrm{~cm}$ de diâmetro e $39 \mathrm{~cm}$ de altura, preenchido com água a uma temperatura controlada de $25^{\circ} \mathrm{C} \pm{ }^{\circ} \mathrm{C}$, dividido em quatro quadrantes imaginários (para efeito de registros comportamentais) numerados em sentido horário (Q1, Q2, Q3 e Q4) com uma plataforma circular, preta, de 12 $\mathrm{cm}$ de diâmetro e $25 \mathrm{~cm}$ de altura, submersa $1,5 \mathrm{~cm}$ abaixo do nível da água, colocada dentro do tanque numa posição fixa no centro de um dos quatro quadrantes imaginários (Q1). O labirinto aquático permaneceu no centro de uma sala, sobre uma estrutura de $50 \mathrm{~cm}$ de altura construída em madeira maciça. Em áreas externas ao tanque foram oferecidas algumas pistas visuais - tais como figuras aleatórias nas paredes, as janelas e a porta da sala. Figura retirada e adaptada de: Lynn Talton, 2007. Núcleo de testes comportamentais da Universidade da Califórnia, Los Angeles, EUA. Disponível em: http://btc.bol.ucla.edu/

\subsection{Análises bioquímicas de marcadores da doença de Alzheimer}

\subsection{1 - Proteína Tau}

Após o teste comportamental aos 12 meses de idade, os animais foram eutanasiados para coleta do tecido cerebral de interesse. Os ratos foram anestesiados por inalação de isoflurano (BioChimico), seguido de eutanásia por decapitação. Os cérebros foram extraídos e dissecados para coleta do hipocampo dorsal e córtex pré-frontal. Os tecidos foram armazenados em microtubos de $1,5 \mathrm{~mL}$ à $-80^{\circ} \mathrm{C}$ até o momento do preparo dos extratos para análise bioquímica. Para a avaliação dos níveis de um dos biomarcadores clássicos da doença de Alzheimer, a proteína Tau hiperfosforilada (pTau), as amostras utilizadas foram extratos desnaturantes de hipocampo dorsal e córtex pré-frontal de ratos WAR adultos (12 meses), preparados de acordo com Petry e colaboradores (2014), com adaptações. Para cada 
miligrama de tecido utilizado, adicionou-se 10 volumes de tampão RIPA modificado (50 mM Tris, $150 \mathrm{mM} \mathrm{NaCl}, 1 \mathrm{mM}$ EDTA, $1 \%$ Triton X-100 e 0,1\% SDS, pH 7,5) gelado e suplementado com coquetel inibidor de proteases (1:100, Sigma), fluoreto de sódio (NaF, 10 $\mathrm{mM})$ e ortovanadato de sódio $\left(\mathrm{Na}_{3} \mathrm{VO}_{4}, 10 \mathrm{mM}\right)$. As amostras foram homogeneizadas com o auxílio de um potter elétrico (Kimble Chase), por 3 ciclos de 10 segundos, e em seguida, foram submetidas à centrifugação por 10 minutos a $10000 \mathrm{x} \mathrm{g}, \mathrm{a} 4^{\circ} \mathrm{C}$. Os sobrenadantes foram transferidos para novos microtubos de $1,5 \mathrm{~mL}$ e utilizados para análises bioquímicas por Western Blotting. Antes da realização das análises bioquímicas, a concentração de proteína total de cada um dos extratos foi mensurada pelo método de Bradford (1976), utilizando o reagente comercial de Bradford (BioRad), em microplaca de 96 poços de fundo chato. Para tanto, foi usada curva-padrão de albumina de soro bovino (BSA, Sigma) diluída em PBS 1x, em diferentes concentrações - 12,5 $\mu \mathrm{g} / \mathrm{mL}, 25 \mu \mathrm{g} / \mathrm{mL}, 50 \mu \mathrm{g} / \mathrm{mL}, 75 \mu \mathrm{g} / \mathrm{mL}$ e $100 \mu \mathrm{g} / \mathrm{mL}$. Uma pequena alíquota de cada amostra de extrato foi diluída em PBS 1x (1:200). Foram usados $20 \mu \mathrm{L}$ de amostra e $180 \mu \mathrm{L}$ do reagente de Bradford por poço, sempre em triplicata. As placas foram lidas em leitor de microplacas VersaMax ${ }^{\mathrm{TM}}$ ELISA Microplate Reader (Molecular Devices), em comprimento de onda de $595 \mathrm{~nm}$.

Para a quantificação dos níveis de pTau, bem como de Tau total, utilizou-se $40 \mu \mathrm{g}$ de proteína total dos extratos na eletroforese (SDS-PAGE). As amostras foram preparadas em tampão de amostra (concentrações finais: 0,0625 M Tris-Cl, 2\% SDS, 10\% v/v glicerol, 0,1 $\mathrm{M}$ ditiotreitol, 0,01\% azul de bromofenol, $\mathrm{pH} 6,8$ ) e submetidas à fervura a $100^{\circ} \mathrm{C}$ por 5 minutos. A concentração do gel de separação foi $12 \%$ (12\% acrilamida, $0,32 \%$ bis-acrilamida, $375 \mathrm{mM}$ Tris, 0,01\% SDS, 0,01\% PSA, 0,08\% TEMED, em $\mathrm{H}_{2} \mathrm{O}$ ), e a corrida procedeu sob voltagem constante de $90 \mathrm{~V}$ por 2 horas e 30 minutos, em tampão de corrida (0,025 M Tris, 0,192 M glicina, 0,1\% SDS, pH 8.3). A transferência ocorreu em sistema semi-seco TransBlot ${ }^{\circledR}$ Turbo ${ }^{\mathrm{TM}}$ Transfer System (Bio-Rad) a $300 \mathrm{~mA}$ durante 40 minutos, em tampão de transferência (48 mM Tris, $39 \mathrm{mM}$ glicina, 20\% metanol, 0,0375 \% SDS), segundo recomendações do fabricante, e utilizou-se membrana de nitrocelulose $0,45 \mu \mathrm{m}$ (GE Healthcare Life Sciences). O bloqueio da membrana foi realizado por incubação em solução de leite em pó desnatado 5\% diluído em TBS-T (Tris-buffered saline: $20 \mathrm{mM}$ Tris pH 7,5, $150 \mathrm{nM} \mathrm{NaCl}, 0,1 \%$ Tween 20), por 1 hora, com agitação suave, seguida de lavagem da membrana em TBS-T por 3 vezes de 10 minutos, sob agitação. Posteriormente, procedeu-se à incubação da membrana com o anticorpo primário, diluído em solução BSA/TBS-T 5\%, a $4^{\circ} \mathrm{C}$ e sob agitação suave, overnight. O anticorpo primário utilizado foi o anti-Tau (phospho S396, Abcam) ou o anti-Tau [E178] (Abcam), ambos na concentração 1:1000. Após nova 
etapa de lavagem da membrana em solução TBS-T (3 x 10 minutos), procedeu-se à incubação com o anticorpo secundário ECL anti-rabbit IgG HRP (Amersham) 1:3000, diluído em solução BSA/TBS-T 5\%, por 1 hora a $25^{\circ} \mathrm{C}$ e sob agitação suave. Após a incubação, realizouse nova lavagem da membrana, como já descrito. A revelação foi feita com o kit Amersham ECL Prime Western Blotting Detection Reagent (GE Healthcare Life Sciences) usando 250 $\mu \mathrm{L}$ da solução $\mathrm{A}+250 \mu \mathrm{L}$ da solução B. O reagente foi incubado por 3 min com a membrana, e as imagens foram capturadas usando o fotodocumentador ChemiDoc (Bio-Rad) acoplado a um sistema digital e software ImageQuant ${ }^{T M} 3.5$ (GE Healthcare Life Sciences). Foi estabelecido um padrão de captura de 30 frames, sendo os 5 primeiros com intervalos de 5 segundos entre si, do $6^{\circ}$ ao $10^{\circ}$ com intervalos de 10 segundos, do $11^{\circ}$ ao $20^{\circ}$ com intervalos de 20 segundos, e do $21^{\circ}$ ao $30^{\circ}$ com intervalos de 30 segundos. Os frames escolhidos para a realização da quantificação foram os que imediatamente precederam à indicação de saturação do sinal das bandas. A quantificação dos níveis das proteínas foi realizada com auxílio do software GelAnalyzer 2010 (http://www.gelanalyzer.com/). Em todos os WB, a normalização do nível das proteínas analisadas foi feita utilizando-se como controle de carregamento os níveis da $\beta$-actina, obtidos usando as mesmas membranas. Para isto, após a etapa de revelação descrita anteriormente, as membranas foram submetidas ao processo de deblotting, que consiste na sua incubação em solução de stripping (10\% SDS, 100 mM glicina, 0,1\% NP40, $\mathrm{pH} 2,5$ ) por 30 minutos sob agitação vigorosa, seguida de etapas de lavagem em TBS-T, como já descrito. As membranas passaram por nova etapa de bloqueio, lavagem, e incubação com o anticorpo anti- $\beta$-actina (EMD Millipore), diluído 1:20000 em solução BSA/TBS-T 3\%, por 1 hora a $25^{\circ} \mathrm{C}$ e sob agitação suave. As membranas foram novamente lavadas e, posteriormente, incubadas com o anticorpo secundário anti-mouse IgG HRP (Amersham), diluído 1:3000 em BSA/TBS-T 3\%, por 1 hora a $25^{\circ} \mathrm{C}$, sob agitação suave. Após lavagem das membranas, procedeu-se às etapas de revelação e quantificação, como já descrito. A análise estatística dos dados incluiu o teste de normalidade de Shapiro-Wilk $($ alpha $=0,05)$, seguido de teste-T Student não-pareado com correção de Welch (para os dados com distribuição normal), considerando-se p<0,05 como significância estatística. Já os dados sem distribuição normal foram submetidos ao teste de Mann-Whitney, com $\mathrm{p}<0,05$ como significância estatística. Todos os testes estatísticos foram realizados pelo software GraphPad Prism 6.01.

\subsection{2 - Peptídeo $\beta$-amiloide}

Para a quantificação dos níveis do outro biomarcador clássico da doença de Alzheimer, o peptídeo $\beta$-amiloide $(\mathrm{A} \beta)$, as amostras utilizadas foram extratos não- 
desnaturantes de hipocampo dorsal de ratos WAR adultos (12 meses), preparados de acordo com o que foi descrito por Schaefer e colaboradores (2006), com adaptações. A única diferença com relação ao preparo dos extratos desnaturantes usados para dosagem da proteína Tau (descrito anteriormente) é o uso de PBS 1x (Laborclin) gelado e suplementado com coquetel inibidor de proteases, $\mathrm{NaF}$ e $\mathrm{Na}_{3} \mathrm{VO}_{4}$, nas mesmas concentrações descritas anteriormente, para a homogeneização dos tecidos. Da mesma forma, os sobrenadantes gerados foram utilizados para as análises bioquímicas, inicialmente pelo método de ELISA, ou armazenados à $-20^{\circ} \mathrm{C}$ para posterior análise por Western Blotting. A análise dos níveis de $\mathrm{A} \beta$ na fração solúvel dos extratos não-desnaturantes de hipocampo dorsal de ratos WAR adultos, por ELISA, foi realizada utilizando-se um protocolo baseado no descrito por Johnson-Wood e colaboradores (1997), com adaptações. Microplacas de 96 poços de fundo chato (Corning) foram sensibilizadas com $80 \mu \mathrm{L}$ de anticorpo anti- $\beta$-amiloide (DE2B4, Cell Signalling Technology) diluído 1:1000 em PBS 1x, seguido de incubação a $4^{\circ} \mathrm{C}$ sem agitação, overnight. Após a incubação e descarte do conteúdo dos poços, estes foram lavados/bloqueados com $350 \mu \mathrm{L}$ de solução de leite em pó desnatado $3 \%$ em PBS 1x, sob agitação, por 10 minutos. O conteúdo dos poços foi descartado e repetiu-se esta etapa mais duas vezes, sendo que a última incubação foi de 30 minutos. As amostras foram diluídas em solução de BSA/PBS 1x de modo a ficarem com a concentração de proteínas totais a 1 $\mathrm{mg} / \mathrm{mL}$, e a BSA ficar na concentração de 3\%. Além das amostras, o ensaio incluiu uma curva-padrão de peptídeo $\mathrm{A} \beta-42$ humano sintético (AnaSpec) oligomerizado de acordo com o protocolo de Lambert e colaboradores (1998); a solução de oligômeros de A $\beta$-42 foi diluída em PBS 1x nas concentrações de 1 nM, 10 nM e 100 nM. Procedeu-se, então, à incubação de $80 \mu \mathrm{L}$ das amostras nos poços da placa, todos em triplicata, a $4^{\circ} \mathrm{C}$ e rotação suave, overnight. Após a incubação, os poços foram lavados com solução de Tween 20 0,1\% em PBS 1x por 3 vezes de 10 minutos, sob agitação. A etapa seguinte consistiu na incubação com $80 \mu \mathrm{L} /$ poço de solução de anticorpo anti- $\beta$-amiloide (22-35, Sigma) diluído em solução de BSA/PBS 1x a $3 \%$ (1:1000) por 2 horas a temperatura ambiente, sob agitação suave. Após a incubação, descartou-se o conteúdo dos poços e procedeu-se à lavagem, como já descrito. Em seguida, realizou-se a incubação de $80 \mu \mathrm{L}$ de solução de anticorpo secundário ECL anti-rabbit IgG HRP (Amersham) diluído em BSA/PBS 1x (1:3000), em cada poço, por 1 hora a temperatura ambiente, sob agitação suave. $\mathrm{O}$ conteúdo dos poços foi descartado e procedeu-se à nova lavagem, secando a placa ao final. A revelação do ensaio foi realizada através da incubação de $80 \mu \mathrm{L}$ de solução Tetrametilbenzidina (TMB, Sigma) por poço, durante 10 minutos no escuro. Adicionou-se, por fim, $40 \mu \mathrm{L}$ de solução de ácido sulfúrico $0,5 \mathrm{M}$ em cada poço para parar a 
reação, e procedeu-se à leitura da placa no leitor de microplacas VersaMax ${ }^{\mathrm{TM}}$ ELISA Microplate Reader (Molecular Devices), em comprimento de onda de $450 \mathrm{~nm}$. Alternativamente, o peptídeo $\beta$-amiloide foi dosado por Western Blotting. Para tanto, realizou-se SDS-PAGE utilizando gel de separação 15\% (15\% acrilamida, 0,4\% bisacrilamida, $375 \mathrm{mM}$ Tris, 0,01\% SDS, 0,01\% PSA, 0,08\% TEMED, em $\mathrm{H}_{2} \mathrm{O}$ ), sendo a corrida eletroforética realizada por aproximadamente 1 hora, também sob voltagem constante de 90V. O anticorpo primário utilizado no Western Blotting foi o anti- $\beta$-amiloide (22-35) ou o anti- $\beta$-amiloide (DE2B4), ambos diluídos 1:1000 em BSA/PBS 5\%. As etapas de incubação com o anticorpo secundário e revelação foram realizadas como já descrito.

\subsection{Análise da proteína Tau hiperfosforilada por imunoistoquímica}

Os animais foram anestesiados por administração intraperitoneal de solução tiopental sódico $60 \mathrm{mg} / \mathrm{kg}$ (Abbott). Após constatação de aprofundamento anestésico, os animais foram submetidos ao processo de perfusão transcardíaca de PBS $(100 \mathrm{mM}, \mathrm{pH} 7,4)$ seguido de PFA (4\%). Resumidamente, o protocolo consiste na abertura da caixa torácica e o posicionamento de uma cânula na aorta ascendente, através do ventrículo esquerdo, seguido da perfusão de $150 \mathrm{~mL}$ de PBS $100 \mathrm{mM}\left(24 \mathrm{mM} \mathrm{NaH} \mathrm{PO}_{4}, 79 \mathrm{mM} \mathrm{Na} 2 \mathrm{HPO}_{4}, 154 \mathrm{mM} \mathrm{NaCl}\right.$ ) e na sequência, $350 \mathrm{~mL}$ de paraformaldeído (PFA) a $4 \%$ diluído em PBS. O cérebro de cada animal foi retirado com auxílio de material cirúrgico e imediatamente imerso em PFA 4\% para pós-fixação por 2 a 4 horas, sendo posteriormente transferidos à solução de crioproteção (sacarose $20 \%$ em PBS) a $4^{\circ} \mathrm{C}$ até submergirem. Após submersão na sacarose, os cérebros foram congelados em isopentano 99\% (Vetec) resfriado em gelo seco, e estocados no congelador a $-20^{\circ} \mathrm{C}$. Os cérebros foram cortados em secções coronais de $50 \mu \mathrm{m}$ de espessura em criostato Microm HM-550-E (Walldorf), com temperatura variando de $-22^{\circ} \mathrm{C}$ a $-18^{\circ} \mathrm{C}$. As secções seriadas do hipocampo foram coletadas a partir da coordenada anteroposterior $-2,12$ mm referente ao bregma (PAXINOS; WATSON, 1998). Os cortes de um mesmo animal foram armazenados sequencialmente em seis poços de uma placa de cultura contendo solução anticongelante (100 mM PBS, etilenoglicol e glicerol, na proporção de 5:3:2, pH 7,4) e as placas de cultura contendo os cortes foram armazenadas em congelador a $-20^{\circ} \mathrm{C}$. Os ensaios imunoistoquímicos foram realizados com as secções de hipocampo em free floating. Foi utilizada uma placa de cultura de células com 24 poços e fundo chato, na qual cada poço foi usado para as reações de um conjunto de secções de um animal. Foram utilizados cortes coronais do cérebro de ratos Wistar e WAR, de 3-5 meses e 12 meses de idade, sendo 6 animais por grupo e duas secções por animal. Os tecidos receberam banho em PBS $100 \mathrm{mM}$ 
sem agitação, a $4^{\circ} \mathrm{C}$ overnight. No dia seguinte, receberam novos banhos em solução de PBS $100 \mathrm{mM}$ por 3 vezes de 5 minutos à temperatura ambiente, sob agitação rotatória (etapa de lavagem). Em seguida, realizou-se a recuperação antigênica, que consistiu na incubação dos tecidos em solução de SDS/PBS $1 \%$ por 5 minutos, sob rotação suave à temperatura ambiente, seguido de nova etapa lavagem. Os tecidos foram incubados em solução de inibição de peroxidase endógena ( $12 \mathrm{mM} \mathrm{NaH}_{2} \mathrm{PO}_{4}, 39,5 \mathrm{mM} \mathrm{Na}_{2} \mathrm{HPO}_{4}, 77 \mathrm{mM} \mathrm{NaCl}, 20 \%$ metanol, $0,2 \%$ Triton $\mathrm{X}-100,5 \% \mathrm{H}_{2} \mathrm{O}_{2}$, diluídos em $\mathrm{H}_{2} \mathrm{O}$ ) por 45 minutos sob rotação suave, à temperatura ambiente, seguido de nova etapa de lavagem. O passo seguinte foi a incubação dos tecidos em solução de glicina $0,75 \%$ em PBS por 5 minutos com rotação suave, à temperatura ambiente, seguido de nova etapa de lavagem e posterior incubação em solução de bloqueio ( $2 \%$ BSA, 0,2\% Triton X-100, diluídos em PBS) por 2 horas sob rotação suave, à temperatura ambiente. Após o bloqueio, os tecidos foram incubados com o anticorpo primário anti-Tau (phospho S396, Abcam) diluído 1:1000 em solução de bloqueio (1\% BSA, 0,1\% Triton X-100), a $4^{\circ} \mathrm{C}$ sob rotação suave, overnight. Após nova lavagem, os tecidos foram incubados com solução Complement (Kit Polímero Reveal, Spring) por 10 minutos, seguido de incubação com solução HRP-Conjugate (Kit Polímero Reveal, Spring) por 15 minutos, sendo ambas as incubações sob rotação suave à temperatura ambiente. Os tecidos foram submetidos à lavagem e, em seguida, à etapa de revelação, que consiste na incubação destes em solução do kit DAB Peroxidase Substrate (tampão, diaminobenzidina, $\mathrm{H}_{2} \mathrm{O}_{2}$ e cloreto de níquel, na proporção 1:2:1:1 para cada $2,5 \mathrm{~mL}$ de $\mathrm{H}_{2} \mathrm{O}$ destilada, Vector) por 2 minutos e 20 segundos. A reação foi interrompida pela transferência dos tecidos para $\mathrm{H}_{2} \mathrm{O}$ destilada e, posteriormente, para PBS, onde permaneceram até a montagem em lâminas gelatinizadas. Estas foram deixadas para secar por pelo menos $24 \mathrm{~h}$ para adequada adesão do tecido, quando foram, então, submetidas a protocolo de desidratação por etanol em concentração crescente e xilol. O meio de montagem utilizado para colocação de lamínula foi o Entellan (Merck Millipore). As imagens das lâminas foram adquiridas em microscópio Olympus BX-61VS (Olympus), em campo claro e objetiva com aumento de 10 vezes, acoplado a uma câmera pike F505C-VC50 (Allied). A digitalização das imagens foi realizada usando o programa VS-ASW FL versão 2.7 (Olympus). A quantificação dos níveis de Tau fosforilada foi realizada por densitometria óptica, usando o software ImageJ (https://imagej.nih.gov/ij/). Foram utilizadas as imagens das duas secções de cada animal. Para cada secção, realizou-se a quantificação da imuno-marcação em um dos hipocampos (direito ou esquerdo, escolhido aleatoriamente), nas sub-regiões específicas: hilus, lâmina superior da camada molecular (LSCM), lâmina inferior da camada molecular (LICM), CA3-A e CA3-B. Para tal, foram inseridas virtualmente 8 
regiões de interesse (ROI, do inglês Region of Interest) retangulares e idênticas, de área 31,58 $\mu \mathrm{m}^{2}$, em cada uma das sub-regiões hipocampais citadas e também em regiões da imagem em que não havia tecido, para subtração de background. Para cada ROI, foi realizada a quantificação da intensidade dos pixels, em escala de cinza, dentro de suas respectivas áreas, e considerou-se que o nível de imuno-marcação para cada sub-região hipocampal correspondia à média de intensidade dos pixels dos 8 ROI's, inseridos de forma aleatória ao longo de toda a sua extensão, subtraído do valor de background. Os valores das médias de imuno-marcação (em unidades arbitrárias) das sub-regiões hipocampais de cada secção foram plotados em planilha Excel. Para cada animal dos diferentes grupos experimentais, calculou-se a média dos valores de imuno-marcação das secções 1 e 2, para cada sub-região, e os resultados foram agrupados. Desta forma, considerou-se que os níveis de Tau fosforilada de cada sub-região, para cada grupo, correspondia às médias dos valores dos seus respectivos 6 animais. A análise estatística dos dados foi realizada pelo teste ANOVA de duas vias, considerando-se $\mathrm{p}<0,05$ como significância estatística, seguido do teste de múltiplas comparações de Sidak, com o intuito de se verificar o possível efeito de idade e de cepa nos níveis de Tau hiperfosforilada no hipocampo dos ratos pertencentes aos diferentes grupos. 


\section{RESULTADOS}

\subsection{Déficit cognitivo na cepa WAR}

Dados prévios sugeriam um déficit de memória em ratos WAR (OLIVEIRA et al., 2014; CUNHA et al., 2015). No presente estudo, foi analisada a performance de animais WAR de meia idade e adultos (9 e 12 meses, respectivamente) no LAM, um teste que avalia aprendizado e memória espacial hipocampo-dependente (MORRIS, 1981). Em todos os animais de cada cepa/idade foram avaliados os parâmetros latência de fuga, distância navegada e velocidade média de natação.

Durante a fase de aprendizagem dos animais de 9 meses, foi possível verificar que houve diferença entre o desempenho dos grupos apenas para o parâmetro de distância navegada (Fig. 2B), onde o grupo WAR percorreu maiores distâncias para encontrar a plataforma do que o grupo Wistar na $2^{\mathrm{a}}$ e $3^{\mathrm{a}}$ tentativas do bloco 1 (efeito de interação entre os fatores grupos $\mathrm{x}$ tentativas, $\mathrm{p}=0,015974$; teste Post Hoc de Newman-Keuls). Além disso, verificou-se que o treinamento surtiu efeito para os animais de ambos os grupos, já que, de maneira geral, apresentaram redução significativa na latência para encontrar a plataforma (Fig. 2A) entre as tentativas no bloco 1 (efeito de tentativas, $\mathrm{p}=0,000802$; teste ANOVA de duas vias) e no bloco 4 (efeito de tentativas, $\mathrm{p}=0,0,004446$; teste ANOVA de duas vias), bem como redução significativa na distância navegada para encontrar a plataforma no bloco 4 (efeito de tentativas, $\mathrm{p}=0,000001$; teste ANOVA de duas vias). Na velocidade média de natação (não mostrado), houve diferença entre o desempenho dos grupos apenas na tentativa 2 do bloco 1 (efeito de interação entre os fatores grupos $\mathrm{x}$ tentativas, $\mathrm{p}=0,000005$; teste Post Hoc de Newman-Keuls), onde o grupo WAR apresentou um aumento significativo na velocidade média de natação comparado ao grupo Wistar, bem como na tentativa 13 do bloco 4 (efeito de interação entre os fatores grupos x tentativas, $\mathrm{p}=0,000227$; teste Post Hoc de Newman-Keuls), onde foi observado o inverso. Com relação à probe trial (não mostrado), houve uma tendência de maior permanência dos animais de ambos os grupos no quadrante alvo (Q1) e no quadrante 4, quando comparados ao tempo de natação nos quadrantes 2 e 3 (Q1 x Q2: $\mathrm{p}=0,002745 ; \mathrm{Q} 1 \times \mathrm{Q} 3: \mathrm{p}=0,038584$; $4 \times$ Q2: $\mathrm{p}=0,003371 ; \mathrm{Q} 4 \times \mathrm{Q} 3: \mathrm{p}=$ 0,029119; teste Post Hoc de Newman-Keuls). Quando considerados em conjunto, estes dados indicam que os animais de ambos os grupos foram capazes de aprender a tarefa proposta, apesar de os WARs terem apresentado certa dificuldade no início da fase de aprendizagem, como indicado pela análise de distância navegada. 
Para avaliar a retenção, consolidação e evocação da memória sobre o aprendizado adquirido na primeira fase do teste, analisou-se a latência de fuga 24 horas e 7 dias após a última tentativa da fase de aprendizado (Fig. 2C). A análise estatística do teste de retenção de memória revelou que os animais do grupo Wistar apresentaram aumento de latência somente na tentativa realizada 7 dias após a $24^{\mathrm{a}}$ tentativa $(\mathrm{p}=0,032536)$, indicando que não houve déficit de desempenho após 24 horas. Já os animais WAR apresentaram aumento de latência na tentativa realizada 24 horas após a $24^{\mathrm{a}}$ tentativa $(\mathrm{p}=0,000236)$, demonstrando, assim, que estes animais apresentaram um déficit de memória após 24 horas da fase de aprendizagem. Ademais, a performance do grupo WAR na tentativa realizada 24 horas pós-treino também foi significativamente diferente dos Wistar $(\mathrm{p}=0,000289)$.
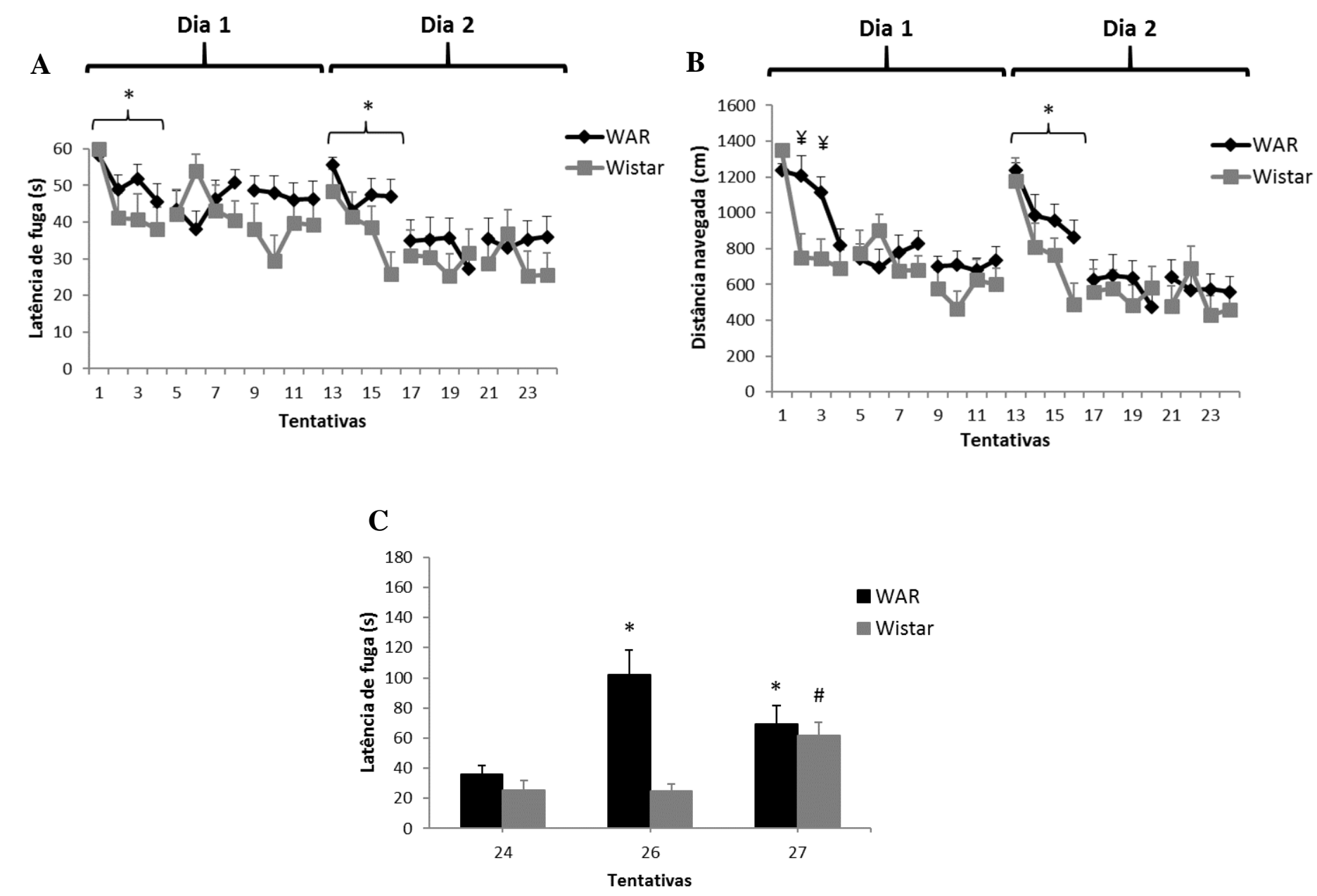
Figura 2 - Déficit de memória espacial em ratos WAR de meia-idade (9 meses) avaliado pelo labirinto aquático de Morris (LAM). Ratos Wistar $(n=11)$ e WAR $(n=17)$ foram submetidos ao LAM. Os parâmetros avaliados foram latência de fuga (A) e distância navegada (B) durante a fase de aprendizagem. A retenção de memória (C) foi avaliada após 24 horas (tentativa 26) e 7 dias (tentativa 27) da fase de aprendizagem, sendo as comparações feitas em relação à sua última tentativa (tentativa 24). Dados apresentados como média \pm EPM de tempo (segundos) ou de distância navegada (centímetros) necessários para encontrar a plataforma. Para os painéis A e B: $(*)$ p $<0,05$ para efeito de tentativas, de acordo com o teste ANOVA de duas vias, e (¥) para efeito de interação entre os fatores grupos x tentativas, de acordo com o teste Post Hoc de Newman-Keuls. Para o painel C: (* e \#) p<0,05 para efeito de interação entre os fatores grupos x tentativas, de acordo com o teste Post Hoc de Newman-Keuls.

Os mesmos animais Wistar e WAR foram submetidos ao LAM aos 12 meses de idade. Foi verificado que houve diferenças entre o desempenho dos grupos na latência de fuga (Fig. 3A) e distância navegada (Fig. 3B). De maneira geral, os animais do grupo WAR apresentaram maior latência para encontrar a plataforma que os animais Wistar no bloco 2 (efeito de grupos, $\mathrm{p}=0,036185$; teste ANOVA de duas vias) e no bloco 3 (efeito de grupos, $\mathrm{p}$ = 0,002206; teste ANOVA de duas vias). Da mesma forma, os animais do grupo WAR apresentaram aumento na distância navegada em comparação aos Wistar no bloco 2 (efeito de grupos, $\mathrm{p}=0,012169$; teste ANOVA de duas vias) e no bloco 3 (efeito de grupos, $\mathrm{p}=$ 0,001374; teste ANOVA de duas vias). Além disso, verificou-se que o treinamento surtiu efeito para os animais de ambos os grupos, já que, de maneira geral, apresentaram redução significativa na latência para encontrar a plataforma, com a progressão das tentativas no bloco 1 (efeito de tentativas, $\mathrm{p}=0,002132$; teste ANOVA de duas vias). Nesse mesmo bloco, houve ainda redução significativa na distância navegada para encontrar a plataforma (efeito de tentativas, $\mathrm{p}=0,000057$; teste ANOVA de duas vias). Em termos de velocidade média de natação (não mostrado), houve diferença entre o desempenho dos grupos apenas no bloco 4 (efeito de grupos, $\mathrm{p}=0,049380$, teste ANOVA de duas vias), onde o grupo Wistar apresentou aumento significativo na velocidade média de natação comparado ao grupo WAR. Com relação aos dados da probe trial (não mostrado), observou-se que o tempo de natação dos animais de ambos os grupos no quadrante alvo (Q1) foi maior em relação ao dos outros quadrantes (Q1 x Q2: p = 0,000156; Q1 x Q3: p = 0,000802; Q1 x Q4: p = 0,000408; teste Post Hoc de Newman-Keuls), indicando que os animais apresentaram precisão de localização espacial, mesmo na ausência da plataforma. Estes dados em conjunto indicam que os animais de ambos os grupos foram capazes de reassimilar a tarefa proposta, apesar de o grupo WAR apresentar maior dificuldade, como demonstrado pelos parâmetros de latência de fuga e distância navegada. 
A análise do teste de retenção de memória demonstrou que os animais de ambos os grupos não apresentaram quaisquer diferenças de performance, em nenhuma das tentativas consideradas (Fig. 3C
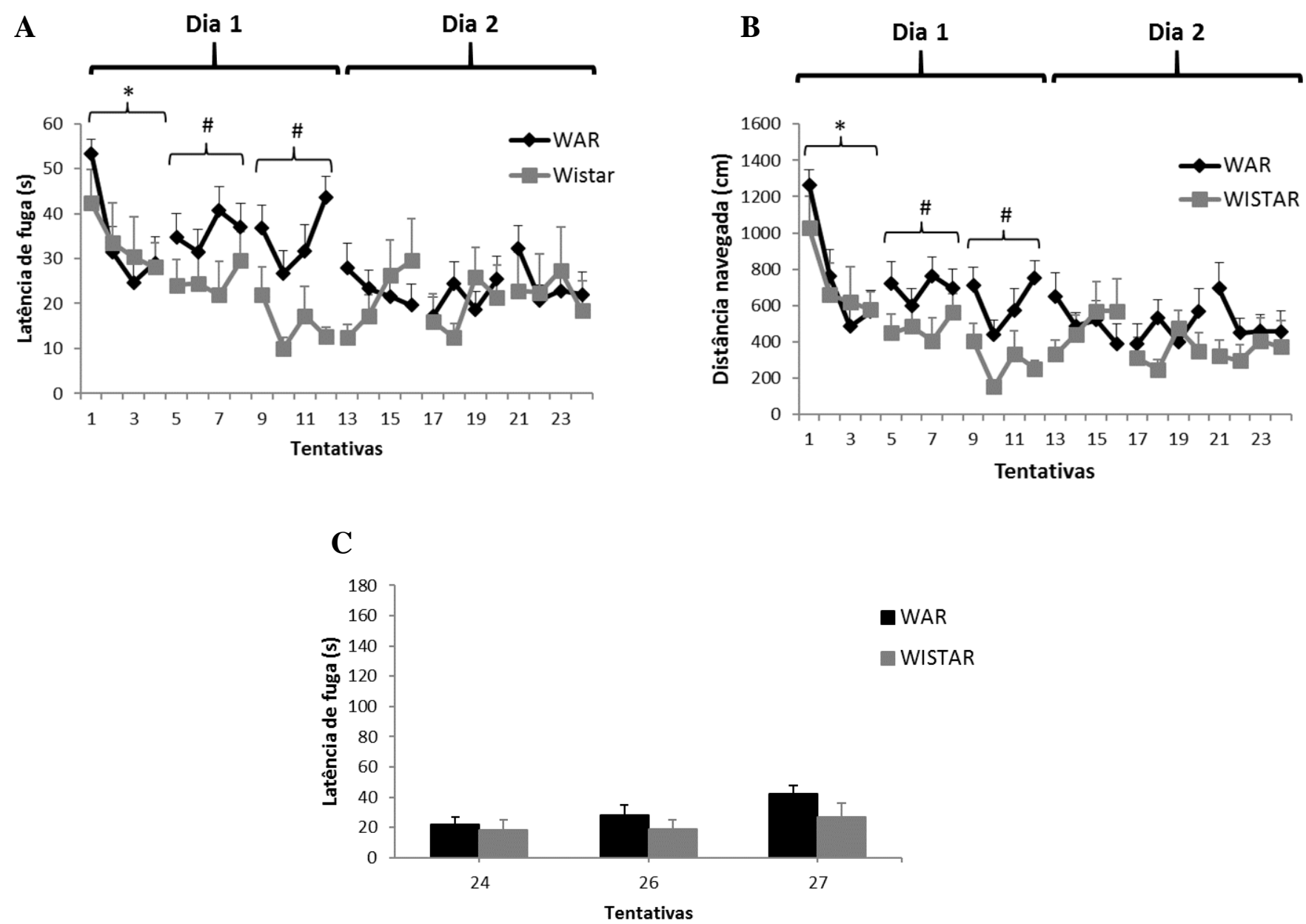

Figura 3 - Déficit de aprendizagem em ratos WAR de meia idade (12 meses) avaliado pelo LAM. Ratos Wistar $(n=8)$ e WAR $(n=15)$ foram submetidos ao LAM. Os parâmetros avaliados foram latência de fuga (A) e distância navegada (B) durante a fase de aprendizagem. A retenção de memória (C) foi avaliada após 24 horas (tentativa 26) e 7 dias (tentativa 27) da fase de aprendizagem, sendo as comparações feitas em relação à sua última tentativa (tentativa 24). Dados apresentados como média \pm EPM de tempo (segundos) ou de distância navegada (centímetros) necessários para encontrar a plataforma. Para os painéis A e B: $(*) p<0,05$ para efeito de tentativas e (\#) $\mathrm{p}<0,05$ para efeito de grupos, de acordo com o teste ANOVA de duas vias.

\subsection{Análises dos biomarcadores da doença de Alzheimer}

\subsection{1 - Proteína Tau}

Após verificado que os animais WAR apresentam déficits de aprendizagem e de memória espacial, refletindo um fenótipo comportamental semelhante, em alguns aspectos, ao 
apresentado por pacientes portadores de demência do tipo Alzheimer, buscou-se avaliar aspectos bioquímicos semelhantes aos que ocorrem na DA, e que possivelmente explicassem os déficits cognitivos observados. Para tanto, a primeira estratégia utilizada foi a análise de um dos biomarcadores clássicos da DA, a proteína Tau hiperfosforilada (pTau), em extratos de hipocampo dorsal - já que o hipocampo é a principal estrutura cerebral responsável pela retenção memória (LEUNER; GOULD, 2010), e é precocemente afetada na DA (SERRANOPOZO et al., 2011; SCHÖLL et al., 2016), além do fato de que a região dorsal, em específico, está intimamente relacionada às funções que coordenam a memória espacial (BANNERMAN et al., 2014) - e também de córtex pré-frontal de animais WAR adultos (12 meses) - pois esta região exerce, juntamente com o hipocampo, importante papel na cognição espacial e planejamento de ações (JO et al., 2007; MARTINET et al., 2011). As amostras de extratos desnaturantes das regiões cerebrais mencionadas foram submetidas a SDS/PAGE seguido de Western Blotting, para a realização da quantificação dos níveis de Tau hiperfosforilada no resíduo de serina localizado na posição 396, bem como para avaliar os níveis totais desta proteína (Tau total) e a relação entre pTau e Tau total. Foi considerado que as 3 bandas localizadas entre 50 e $75 \mathrm{kDa}$ são referentes a diferentes isoformas da proteína Tau íntegra, como demonstrado no estudo realizado por Taniguchi-Watanabe e colaboradores (2016). Portanto, a soma dos valores da quantificação de cada banda, em uma mesma canaleta, foi considerada como o nível da proteína fosforilada ou total, dependendo do anticorpo utilizado.

Durante a realização dos Western Blottings para pTau e Tau total com as amostras de ambos os grupos experimentais, foi constatado que quando o extrato utilizado para este tipo de análise não era fresco - ou seja, era confeccionado, congelado a $-20^{\circ} \mathrm{C}$ por um determinado período, e depois descongelado para, então, ser submetido ao SDS/PAGE e Western Blotting - havia a presença consistente de uma banda adicional de aproximadamente $25 \mathrm{kDa}$, tanto nos extratos de córtex pré-frontal (Figs. 4A e B) quanto nos de hipocampo (Figs. 4C e D), independente da cepa do animal. Vale a pena ressaltar que, na maioria dos casos, a presença desta banda de $\sim 25 \mathrm{kDa}$ ocorreu concomitantemente com a redução na intensidade das 3 bandas relativas às isoformas de Tau íntegra, localizadas no intervalo entre 50 e 75 kDa, sugerindo que esta banda adicional representa um produto de degradação gerado pelo processo de armazenamento da amostra. Para testar essa suspeita, realizou-se o SDS-PAGE e WB com extratos frescos (sem a etapa de congelamento) provenientes das mesmas amostras dos mesmos animais. Para nossa surpresa, nessa condição, a banda de $25 \mathrm{kDa}$ não foi detectada (Figs. 4A, B, C e D). Foi possível, ainda, notar que este efeito parece ser específico 
para a proteína Tau (hiperfosforilada e total), já que quando se utilizou as mesmas membranas para a revelação da proteína $\beta$-actina (Fig. 4E), não houve diferenças na integridade da banda relativa a esta proteína, e nem aparecimento de bandas adicionais, para todas as amostras, independente do estado de conservação do extrato (fresco ou congelado/descongelado), da região cerebral de origem, ou da cepa do animal. 
A Córtex pré-frontal - pTau
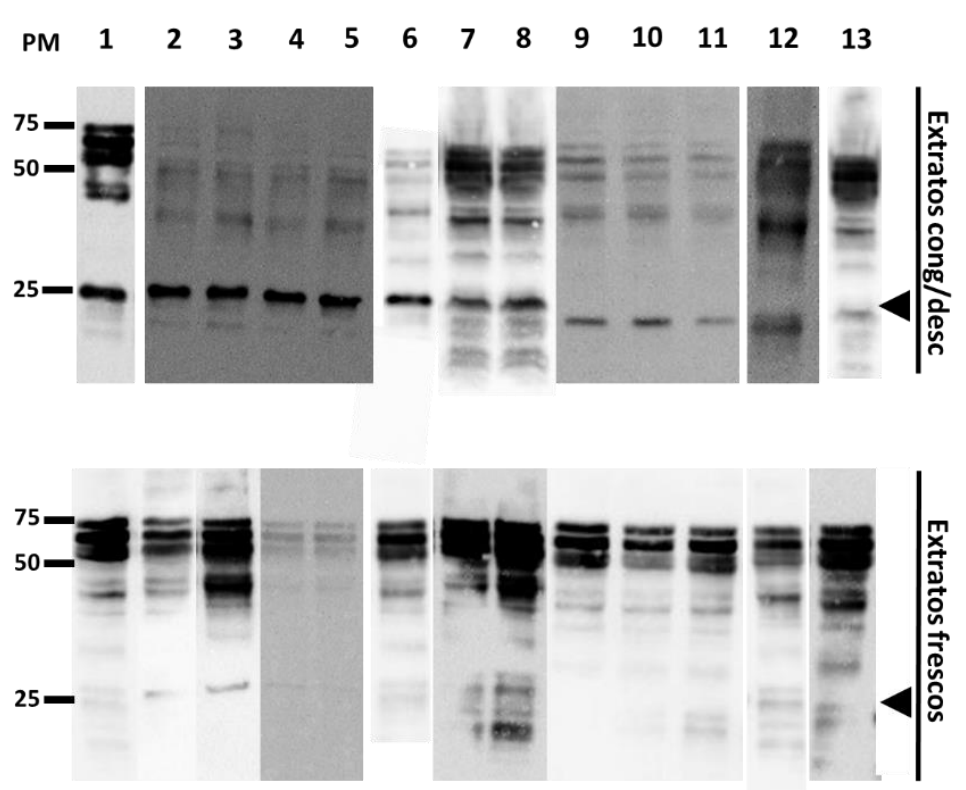

Hipocampo dorsal - pTau

C
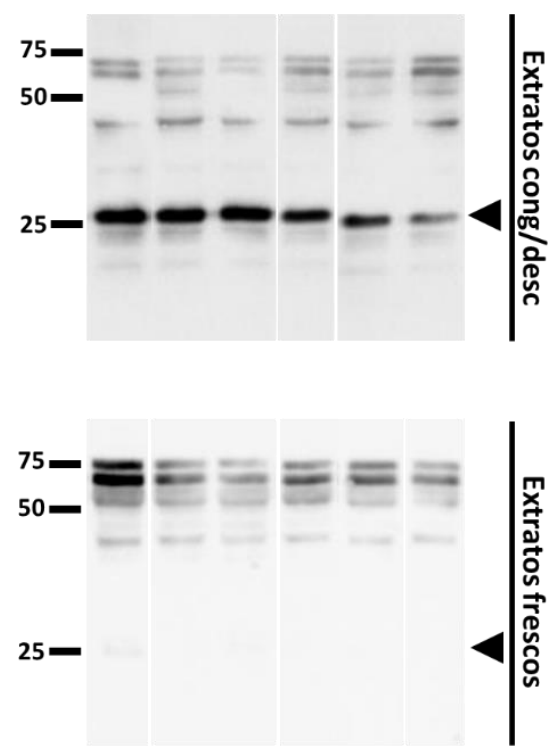

\begin{tabular}{lllll} 
E & \multicolumn{4}{l}{ Córtex pré-frontal } \\
\cline { 2 - 6 } & $\begin{array}{lllll}1 & 2 & 3 & 4 & 5\end{array}$
\end{tabular}

$\beta$-actina

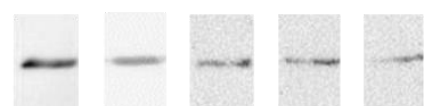

$$
\text { a }
$$$$
\text { - - - - }
$$

B Córtex pré-frontal - Tau total

$\begin{array}{lllllllllllll}\mathrm{PM} & 1 & 2 & 3 & 4 & 5 & 6 & 7 & 8 & 9 & 10 & 11 & 12\end{array}$
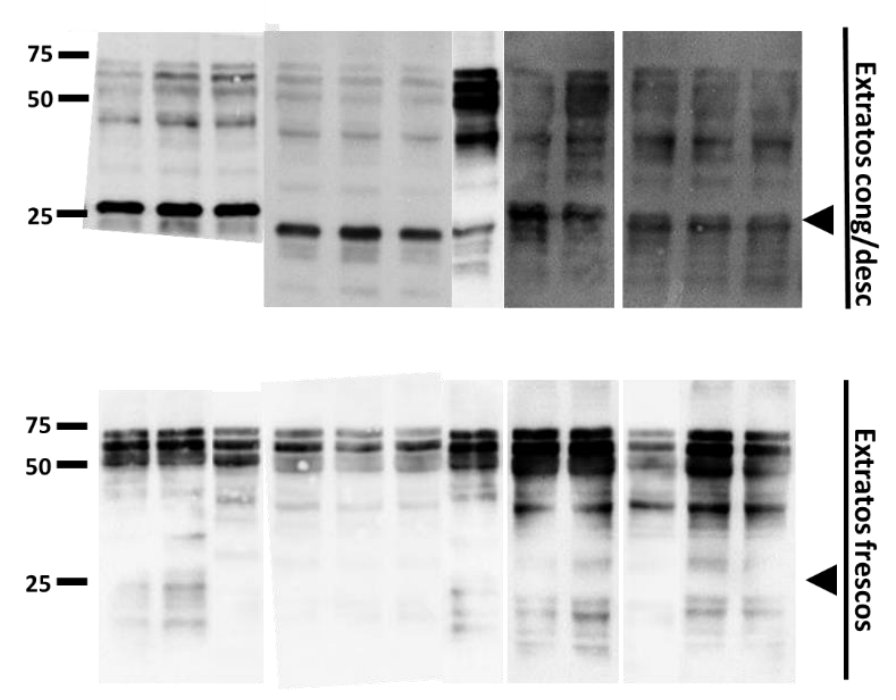

Hipocampo dorsal - Tau total

D
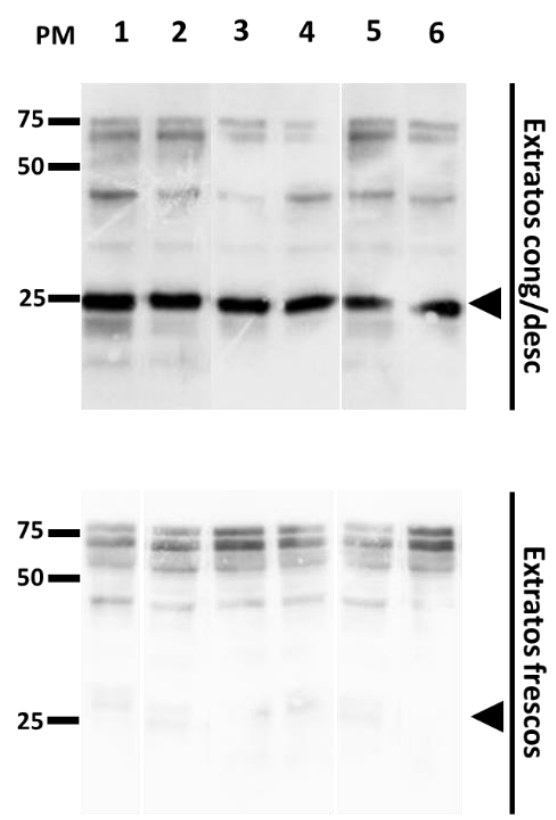

Hipocampo dorsal

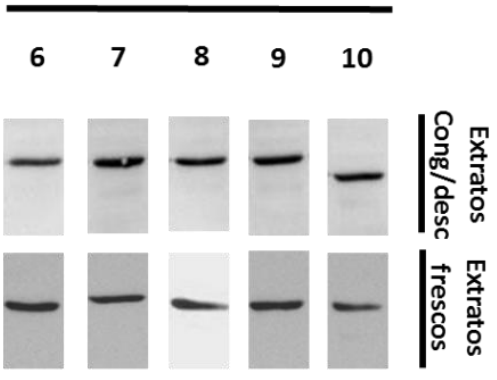


Figura 4 - Detecção de fragmento de degradação da proteína Tau em extratos de hipocampo dorsal e córtex pré-frontal submetidos ao armazenamento por congelamento. Western Blottings realizados para a proteína pTau (A, C) e Tau total (B, D) em extratos frescos e submetidos a congelamento/descongelamento (cong/desc) provenientes de córtex pré-frontal (A, B) ou hipocampo dorsal (C, D). A cabeça de seta indica a presença de uma banda de aproximadamente $25 \mathrm{kDa}$ em extratos cong/desc de córtex pré-frontal e hipocampo para ambos os anticorpos. (E) marcação da proteína controle de carregamento $\beta$-actina em extratos frescos e cong/desc provenientes de córtex pré-frontal ou hipocampo dorsal. Algumas amostras (em A: canaletas 2-8; em B: canaletas 1-3 e 7-9; em C: canaletas 1-3; em D: canaletas 3, 4 e 6; em E: canaletas 3-5, 9 e 10) foram obtidas do cérebro de ratos WAR de 12 meses, enquanto o resto das amostras foi obtida do cérebro de ratos Wistar de mesma idade.

Desta forma, levando-se em consideração estes dados apresentados, procedeu-se à análise dos níveis de pTau e Tau total somente em extratos frescos. Nas análises do hipocampo dorsal, verificou-se que os animais WAR apresentam aumento significativo dos níveis de pTau (Fig. 5B, p < 0,05) e Tau total (fig. 5D, p <0,05) em relação aos animais Wistar de idade pareada. Contudo, não houve diferença significativa na relação pTau/Tau total entre os grupos (Fig. 5E). 

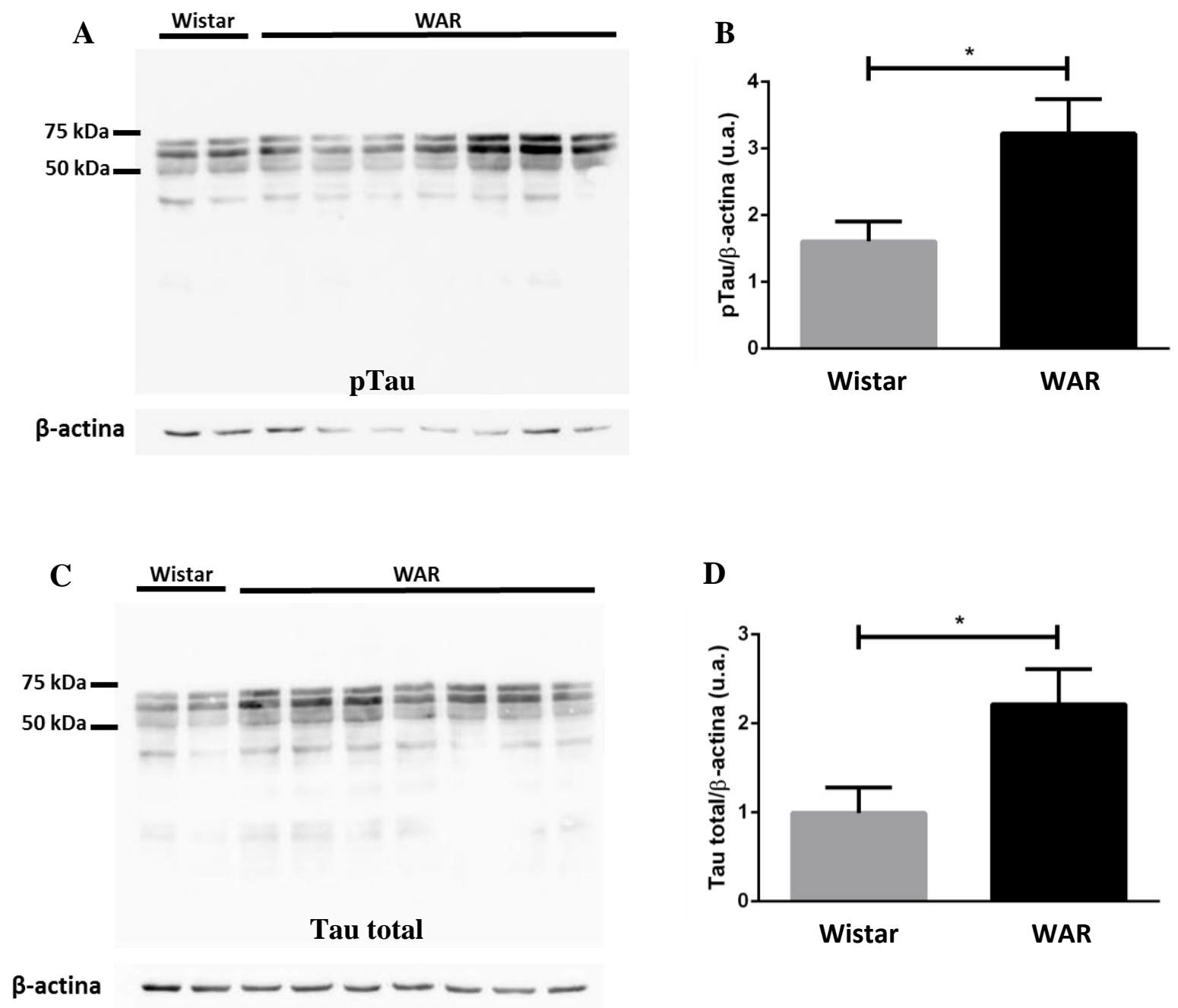

D
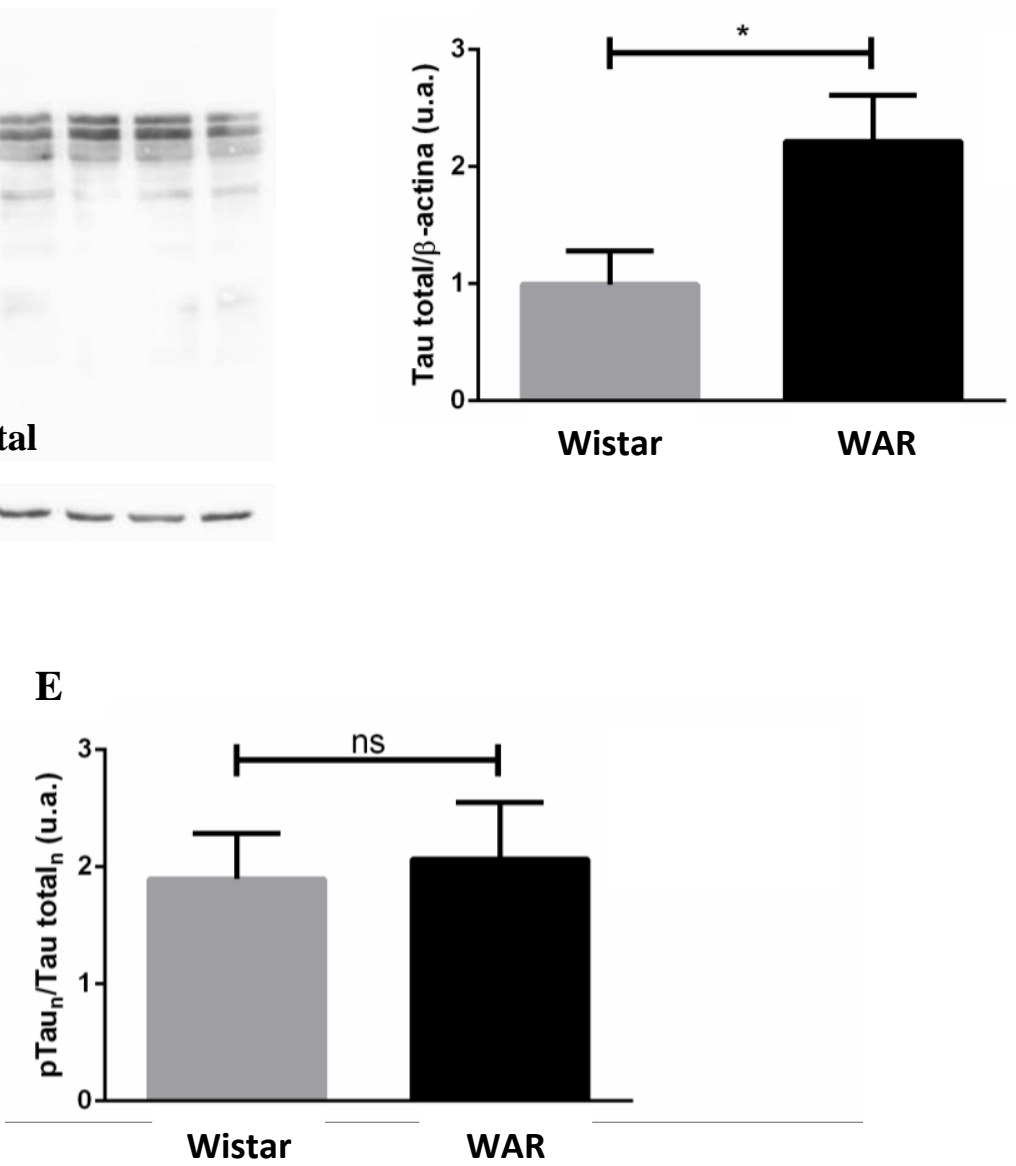

Figura 5 - Quantificação dos níveis da proteína Tau hiperfosforilada (pTau) e total em extratos de hipocampo dorsal de ratos adultos (12 meses). A e C: imagens representativas dos resultados de Western Blotting utilizados para realização de análises semiquantitativas dos níveis de pTau (resíduo Ser-396) e Tau total endógenas, em hipocampo dorsal de ratos Wistar $(n=4)$ e WAR $(n=11)$ de 12 meses. B, D e E: gráficos das quantificações dos níveis de pTau (B) e Tau total (D), além da relação entre pTau e Tau total (E). Valores normalizados pelos níveis de $\beta$-actina. Dados das quantificações foram expressos como média \pm EPM (unidades arbitrárias). 
A análise dos níveis de Tau em córtex pré-frontal mostrou que não houve diferença significativa dos níveis de pTau entre os grupos, a despeito de tendência de aumento do WAR em relação ao grupo Wistar (Fig. 6B). Também não houve diferença significativa dos níveis de Tau total (Fig. 6D) e nem na relação pTau/Tau total (Fig. 6E) entre os grupos.
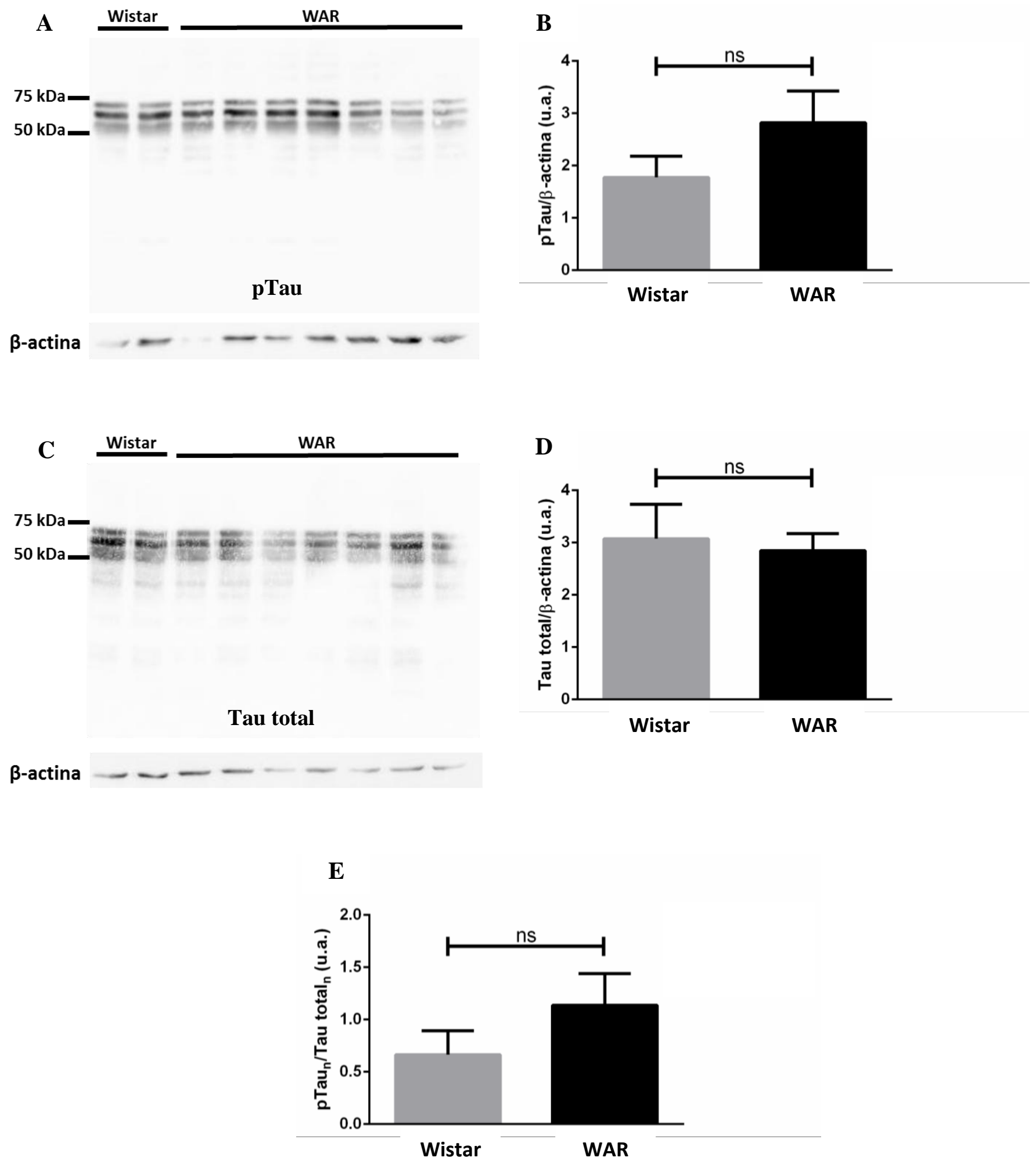
Figura 6 - Quantificação da proteína Tau hiperfosforilada (pTau) e total em extratos de córtex pré-frontal de ratos adultos (12 meses). A e C: imagens representativas dos resultados de Western Blotting utilizados para realização de análises semiquantitativas dos níveis de pTau (resíduo Ser-396) e Tau total endógenas, em córtex pré-frontal de ratos Wistar $(n=3)$ e WAR $(n=10)$ de 12 meses. B, D e E: gráficos das quantificações dos níveis de pTau (B) e Tau total (D), além da relação entre pTau e Tau total (E). Valores normalizados pelos níveis de $\beta$ actina. Dados das quantificações foram expressos como média \pm EPM (unidades arbitrárias).

\subsection{2 - Análise da proteína Tau hiperfosforilada por imunoistoquímica}

A análise semiquantitativa de pTau e Tau total por Western Blotting forneceu dados a respeito dos níveis gerais destes analitos nas amostras de hipocampo dorsal e córtex préfrontal. Porém, este método não é capaz de prover informações sobre a distribuição e a localização destas proteínas no tecido de origem. Uma técnica que fornece este tipo de informação qualitativa, e que foi utilizada para marcação da proteína pTau em secções de hipocampo de ratos Wistar e WAR, é a imunoistoquímica.

A análise qualitativa da imuno-marcação da proteína pTau no hipocampo dos ratos Wistar e WAR, nas idades de 3-5 meses e 12 meses, revelou que o padrão geral de marcação foi semelhante entre todos os animais dos diferentes grupos experimentais (não mostrado). Foi possível observar predominância de marcação de estruturas de aspecto filamentoso, sobretudo nas regiões do hilus e CA-3, sendo estas regiões conhecidas principalmente por constituírem vias de passagem e inervação das terminações axonais (fibras musgosas) das células granulares do giro denteado, além da presença de interneurônios e neurônios de outras classes (OKAZAKI; MOLNÁR; NADLER, 1999; HENZE; URBAN; BARRIONUEVO, 2000). Na camada molecular, também foi possível observar marcação de estruturas filamentosas, porém mais discretas, que correspondem a processos neuronais - axônios provenientes da via perfurante do córtex entorrinal e dendritos das células granulares do giro denteado. Como a proteína Tau participa da montagem e estabilização de microtúbulos, e estes, por sua vez, participam da definição da polaridade dos neurônios, ou seja, direcionam o crescimento de dendritos e axônios, infere-se que a marcação observada corresponda realmente à proteína pTau nas regiões hipocampais observadas (CONDE; CÁCERES, 2009). Desta forma, além da análise qualitativa, realizou-se também a quantificação dos níveis de marcação de pTau para averiguar se há diferenças sub-regionais de fosforilação desta proteína nos diferentes grupos experimentais. A figura 7 mostra uma imagem representativa da marcação obtida, e nela estão destacadas - através de regiões de interesse (ROIs) retangulares de diferentes cores - as áreas selecionadas para a quantificação por densitometria óptica. 


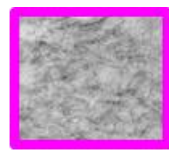

CA3-A

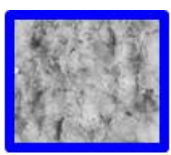

CA3-B

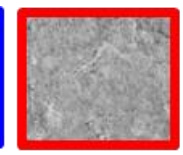

LICM

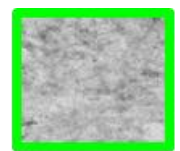

Hilus

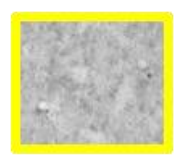

LSCM

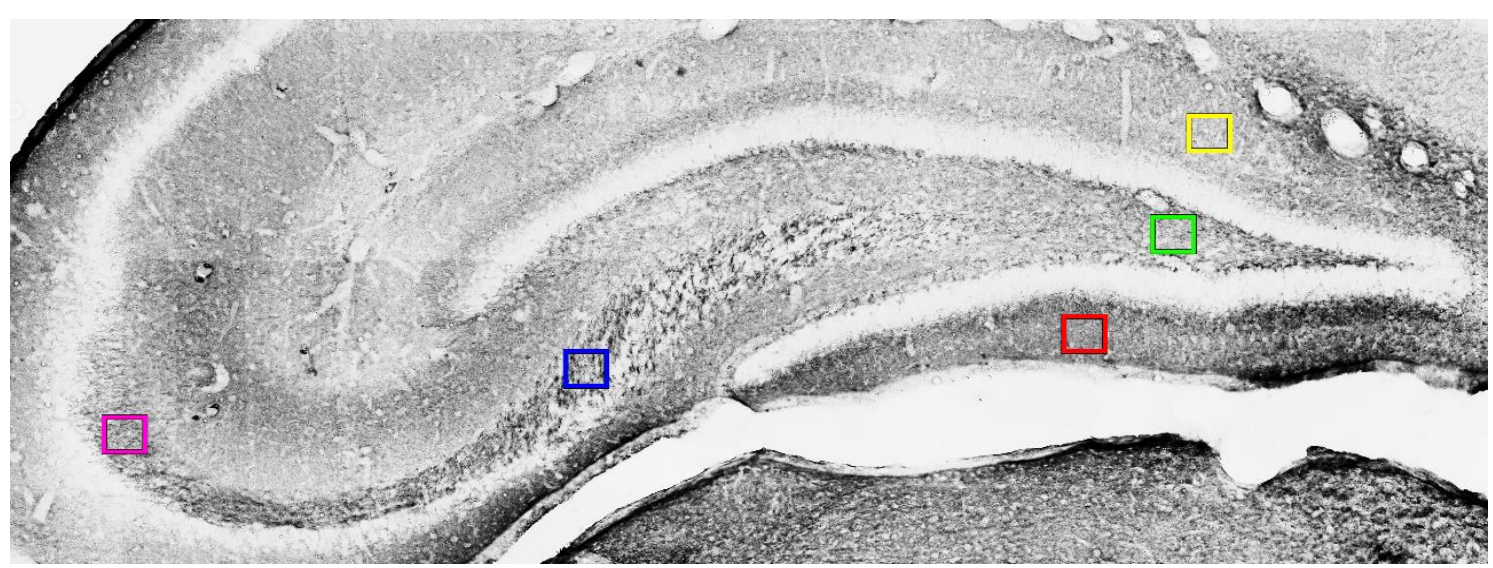

Figura 7 - Padrão de imuno-marcação de pTau em secção de hipocampo de rato Wistar jovem (3-5 meses). Imagem representativa de uma secção coronal de hipocampo de rato Wistar de 3-5 meses imunomarcada para a proteína Tau hiperfosforilada, mostrando as áreas selecionadas para quantificação por densitometria óptica, as quais estão discriminadas pela presença de ROIs retangulares de diferentes cores: hilus (verde), lâmina superior da camada molecular (amarelo), lâmina inferior da camada molecular (vermelho), CA3 A (pink) e CA3-B (azul).

A análise estatística das quantificações para cada região demonstrou que existe efeito de interação entre os fatores idade e cepa (hilus: $\mathrm{p}=0,0016$; lâmina superior da camada molecular: $p=0,0027$; lâmina inferior da camada molecular: $p=0,0016$; CA3-A: $p=0,0007$; CA3-B: $p=0,001)$, indicando que as variáveis consideradas são dependentes e exercem influência nos níveis de pTau. Desta forma, realizou-se o teste de múltiplas comparações de Sidak, onde buscou-se verificar a eventual existência de diferenças nos níveis de pTau tanto entre os grupos de diferentes idades dentro de cada cepa, como também dos grupos com idades pareadas, mas de cepas diferentes. Os resultados para cada área selecionada estão descritos a seguir:

- Hilus: A análise de múltiplas comparações demonstrou que houve diferença significativa nos níveis de pTau entre os animais da mesma cepa, levando-se em consideração a idade como variável avaliada. Para o grupo Wistar, observou-se que os animais de 12 meses apresentam redução significativa dos níveis de pTau em comparação aos animais de 3-5 meses $(\mathrm{p}=0,029)$. Já os animais de 12 meses do grupo WAR apresentaram aumento significativo em relação aos animais de 3-5 meses da 
mesma cepa ( $\mathrm{p}=0,0077)$. Quando a variável avaliada foi a cepa, os resultados das análises permitiram observar que houve diferença significativa nos níveis de pTau entre os animais de idades pareadas; para o grupo de animais de 3-5 meses, observouse que os animais do grupo WAR apresentaram redução significativa dos níveis de pTau em relação aos animais do grupo Wistar $(\mathrm{p}=0,0164)$, enquanto para o grupo de animais de 12 meses, os animais WAR apresentaram aumento significativo em relação aos animais Wistar $(\mathrm{p}=0,0127)$. O resultado da quantificação está ilustrado na figura 8 A.

- Lâmina superior da camada molecular (LSCM): Foi possível observar que houve diferença significativa nos níveis de pTau entre os animais da mesma cepa, levando-se em consideração a idade como variável avaliada; para o grupo Wistar, observou-se que os animais de 12 meses apresentaram redução significativa dos níveis de pTau em comparação aos animais de 3-5 meses ( $\mathrm{p}=0,0127)$, enquanto que os animais de 12 meses do grupo WAR apresentaram aumento significativo em relação aos animais de 3-5 meses da mesma cepa $(\mathrm{p}=0,0429)$. Quando a variável avaliada foi a cepa, os resultados das análises permitiram observar que houve diferença significativa nos níveis de pTau entre os animais de idades pareadas; para o grupo de animais de 3-5 meses, observou-se que os animais do grupo WAR apresentaram redução significativa dos níveis de pTau em relação aos animais do grupo Wistar $(p=0,0172)$, enquanto para o grupo de animais de 12 meses, os animais WAR apresentaram aumento significativo em relação aos animais Wistar $(\mathrm{p}=0,0303)$. O resultado da quantificação está ilustrado na figura 8B.

- Lâmina inferior da camada molecular (LICM): Houve diferença significativa nos níveis de pTau somente entre os animais da cepa Wistar, levando-se em consideração a idade como variável avaliada, visto que os animais de 12 meses apresentaram redução significativa dos níveis de pTau em comparação aos animais de 3-5 meses (p = 0,0023). Já nos animais WAR não houve diferença significativa entre os grupos de 3-5 meses e 12 meses $(\mathrm{p}=0,1654)$. Quando a variável avaliada foi a cepa, os resultados das análises permitiram observar que houve diferença significativa nos níveis de pTau entre os animais de idades pareadas; para o grupo de animais de 3-5 meses, observou-se que os animais do grupo WAR apresentaram redução significativa dos níveis de pTau em relação aos animais do grupo Wistar $(\mathrm{p}=0,009)$, enquanto para o grupo de animais de 12 meses, os animais WAR apresentaram aumento significativo 
em relação aos animais Wistar $(\mathrm{p}=0,0234)$. O resultado da quantificação está ilustrado na figura $8 \mathrm{C}$.

- CA3-A: Houve diferença significativa nos níveis de pTau somente entre os animais da cepa Wistar, levando-se em consideração a idade como variável avaliada, visto que os animais de 12 meses apresentaram redução significativa dos níveis de pTau em comparação aos animais de 3-5 meses $(\mathrm{p}=0,0002)$. Já para os animais da cepa WAR, não houve diferença significativa entre os grupos de 3-5 meses e 12 meses ( $\mathrm{p}=$ 0,5706). Quando a variável avaliada foi a cepa, os resultados das análises permitiram observar que houve diferença significativa nos níveis de pTau entre os animais de idades pareadas; para o grupo de animais de 3-5 meses, observou-se que os animais do grupo WAR apresentaram redução significativa dos níveis de pTau em relação aos animais do grupo Wistar ( $\mathrm{p}=0,0064)$, enquanto para o grupo de animais de 12 meses, os animais WAR apresentaram aumento significativo em relação aos animais Wistar $(\mathrm{p}=0,006)$. O resultado da quantificação está ilustrado na figura 8D.

- CA3-B: Foi possível observar que houve diferença significativa nos níveis de pTau entre os animais da mesma cepa, levando-se em consideração a idade como variável avaliada; para o grupo Wistar, observou-se que os animais de 12 meses apresentaram redução significativa dos níveis de pTau em comparação aos animais de 3-5 meses (p = 0,003), já os animais de 12 meses do grupo WAR apresentaram aumento significativo em relação aos animais de 3-5 meses da mesma cepa ( $p=0,0332)$. Quando a variável avaliada foi a cepa, os resultados das análises permitiram observar que houve diferença significativa nos níveis de pTau entre os animais de idades pareadas somente para o grupo de 3-5 meses, pois os animais do grupo WAR apresentaram redução significativa em relação aos animais do grupo Wistar (p = 0,0022). No entanto, para o grupo de animais de 12 meses, não houve diferença significativa entre as diferentes cepas, mas apenas uma tendência estatística ( $\mathrm{p}=$ 0,0518). O resultado da quantificação está ilustrado na figura $8 \mathrm{E}$. 

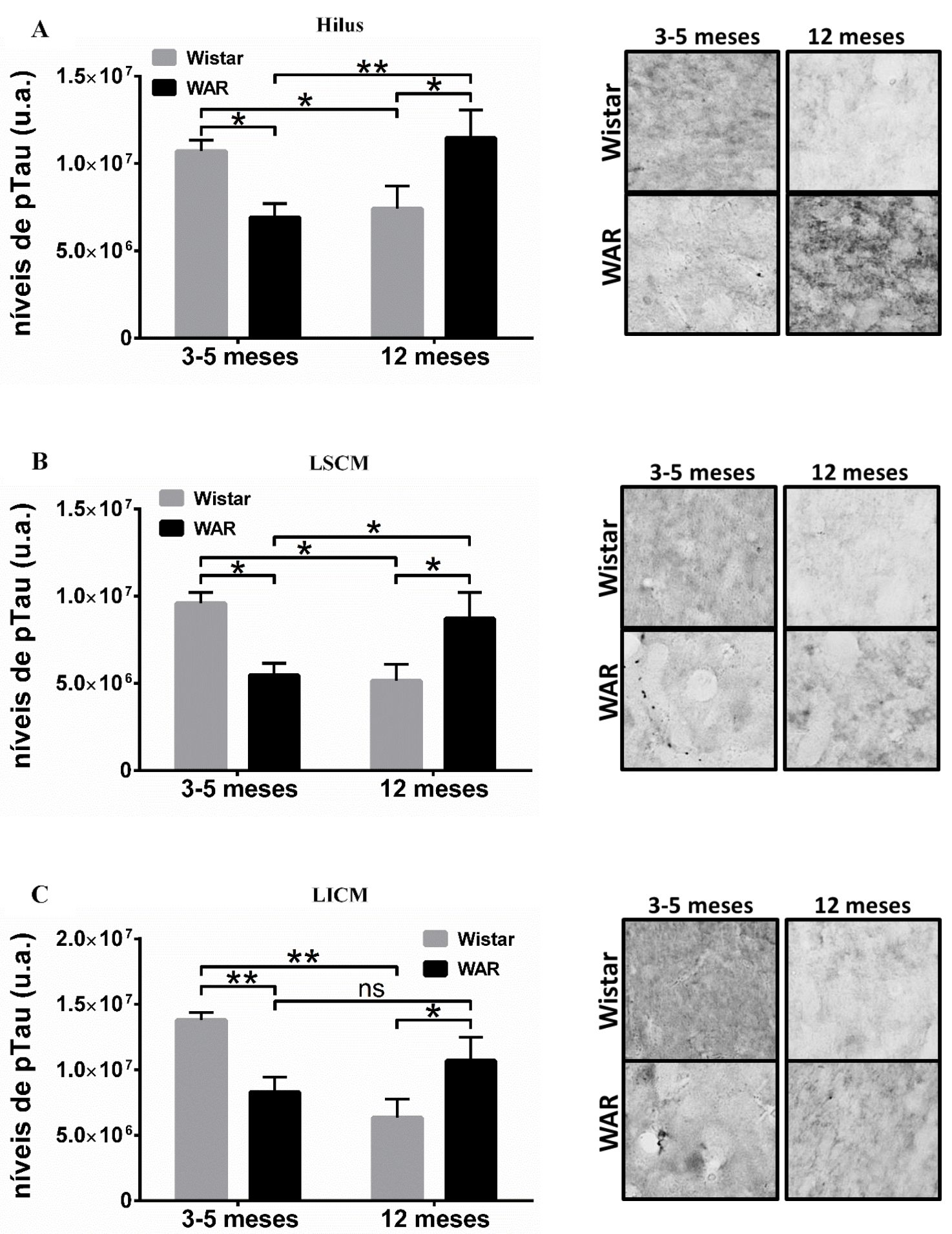

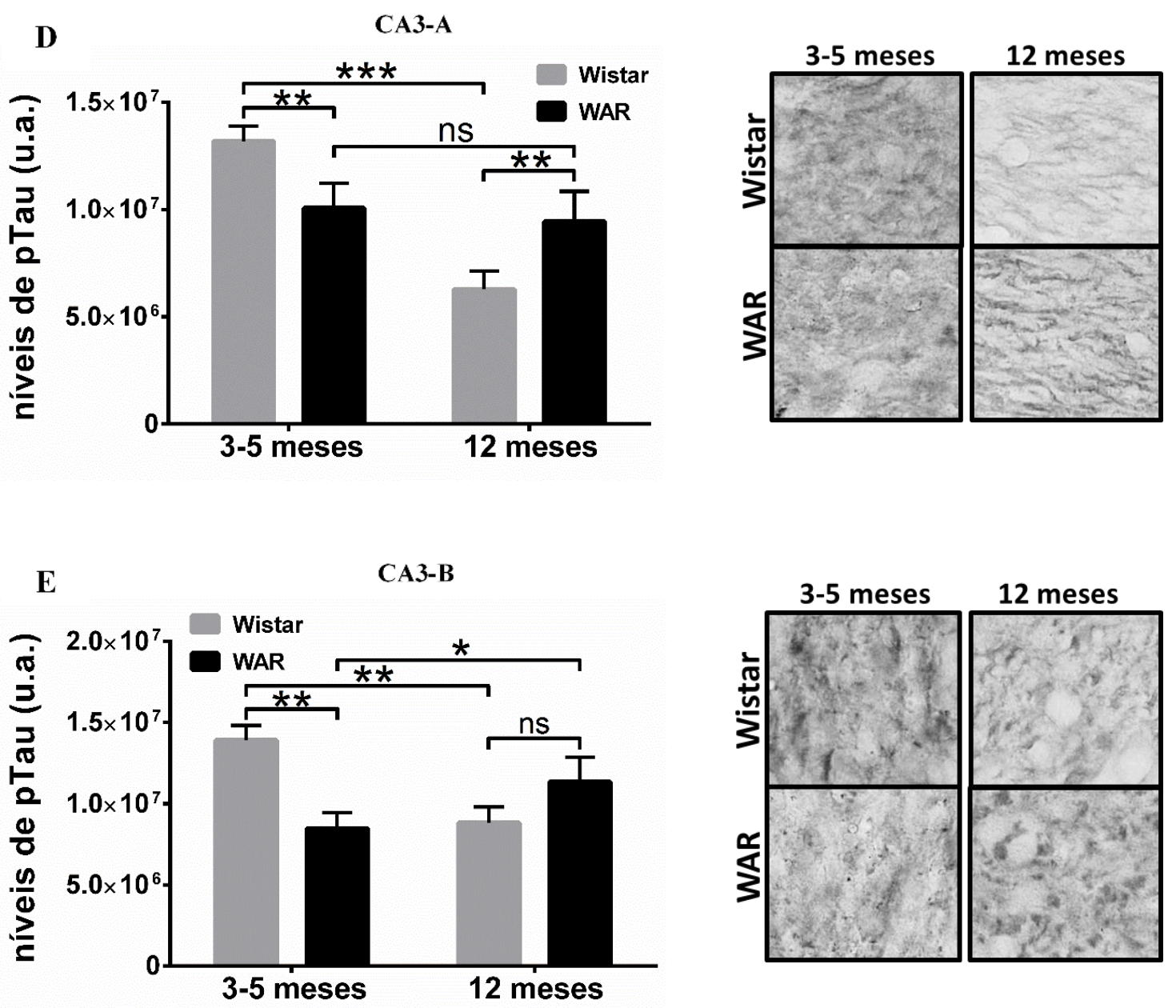

Figura 8 - Acúmulo de proteína Tau hiperfosforilada (pTau) em regiões hipocampais específicas de animais WAR adultos (12 meses). Painéis mostrando os resultados da quantificação dos níveis de pTau em cada área hipocampal selecionada, ao lado de imagens representativas da imuno-marcação obtida para cada grupo experimental. Dados de densitometria óptica foram expressos como média \pm EPM (unidades arbitrárias). (*) $\mathrm{p}<0,05,(* *) \mathrm{p}<0,01$ e $(* * *) \mathrm{p}<0,001(\mathrm{n}=6 /$ grupo).

\subsection{3 - Peptídeo $\beta$-amiloide}

O outro biomarcador clássico da DA, o peptídeo $\beta$-amiloide $(\mathrm{A} \beta)$, também foi avaliado. A primeira estratégia utilizada foi o uso de ELISA sandwich para detecção de A $\beta$ endógeno em extratos de hipocampo dorsal de animais WAR adultos (12 meses).

Além dos extratos de hipocampo dos ratos Wistar e WAR ( $n=4 /$ grupo), e de uma curva-padrão de $\mathrm{A} \beta$, o ensaio contou também com amostras de extrato de hipocampo dorsal (1 mg/mL de proteínas totais, diluído em solução BSA/PBS 3\%) de rato Wistar adulto adicionadas de oligômeros do peptídeo A $\beta-42$ humano sintético na concentração de $100 \mathrm{nM}$ (hipo+A $\beta$ ) ou do veículo de diluição dos oligômeros (hipo+veículo). O resultado obtido neste 
ensaio (Fig. 9A) indicou que o anticorpo de detecção utilizado, o anti- $\beta$-amiloide (22-35), foi eficiente em detectar A $\beta-42$ humano sintético total. As amostras de extrato de hipocampo dos ratos Wistar e WAR apresentaram sinais equivalentes entre si e em relação ao hipo+veículo, e mais baixos do que o hipo+A $\beta$ e curva-padrão a 10 e $100 \mathrm{nM}$. Sendo assim, é possível supor que o anticorpo de detecção também foi capaz de detectar $A \beta$ endógeno. Para comprovar que o sinal detectado nas amostras de hipocampo era, de fato, relativo ao A $\beta$ endógeno dos ratos, realizou-se um teste de especificidade do anticorpo de detecção anti- $\beta$-amiloide (22-35), dessa vez utilizando extratos de tecidos que apresentam baixa ou nula expressão de peptídeo $A \beta$, no caso, pulmão e fígado (ARAI et al., 1991). O resultado deste ensaio (Fig. 9B) demonstrou uma especificidade parcial do anticorpo anti- $\beta$-amiloide (22-35) por A $\beta$ endógeno, já que a amostra de extrato de pulmão apresentou um sinal muito baixo (semelhante ao da amostra da curva-padrão que continha apenas veículo, do ensaio anterior), como esperado de um tecido onde não há expressão de $\mathrm{A} \beta$, mas a amostra de extrato de fígado apresentou um sinal maior que a amostra hipo+veículo, o que pode indicar que o anticorpo de detecção utilizado é inespecífico, ou ainda que no fígado há presença de $\mathrm{A} \beta$ em quantidade maior que o antecipado. Como esperado, as amostras que não receberam a adição do anticorpo primário (controles negativos) não apresentaram sinal.

Como os resultados dos ensaios de ELISA sandwich foram inconclusivos com relação à especificidade do anticorpo anti- $\beta$-amiloide (22-35), uma estratégia alternativa utilizada para se testar a especificidade deste anticorpo, bem como do anticorpo de captura utilizado no ELISA, o anti- $\beta$-amiloide (DE2B4), foi a realização de SDS/PAGE seguido de Western Blotting, cujo objetivo era avaliar se os anticorpos mencionados conseguiriam detectar monômeros de peptídeo A $\beta$ endógeno, de aproximadamente 4,5 kDa, nas amostras de hipocampo dorsal, pulmão e fígado analisadas. O resultado (Fig. 9C) mostrou que nenhum dos anticorpos avaliados foi capaz de detectar monômeros de $\mathrm{A} \beta$ endógeno nas amostras de extrato, nas condições utilizadas. Observou-se apenas a presença de algumas bandas de peso molecular superior a $20 \mathrm{kDa}$ no hipocampo dorsal e fígado com o anticorpo primário anti- $\beta$ amiloide (22-35), que não correspondem a $A \beta$ monomérico. 
A

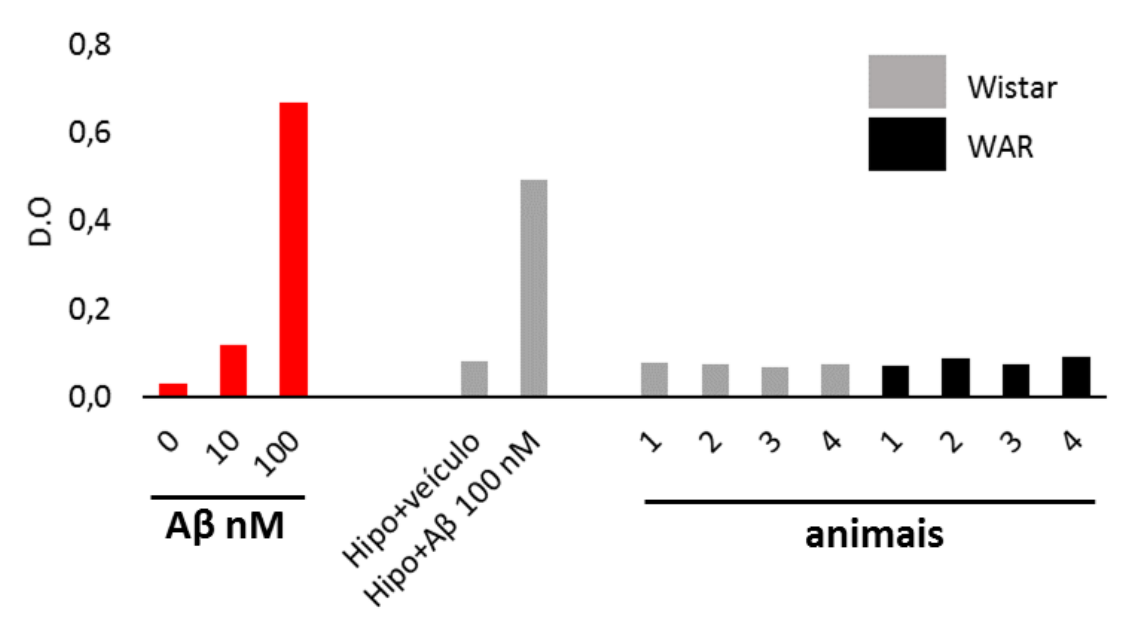

B

C

$\alpha-A \beta$ (22-35) $\alpha-A \beta$ (DE2B4)
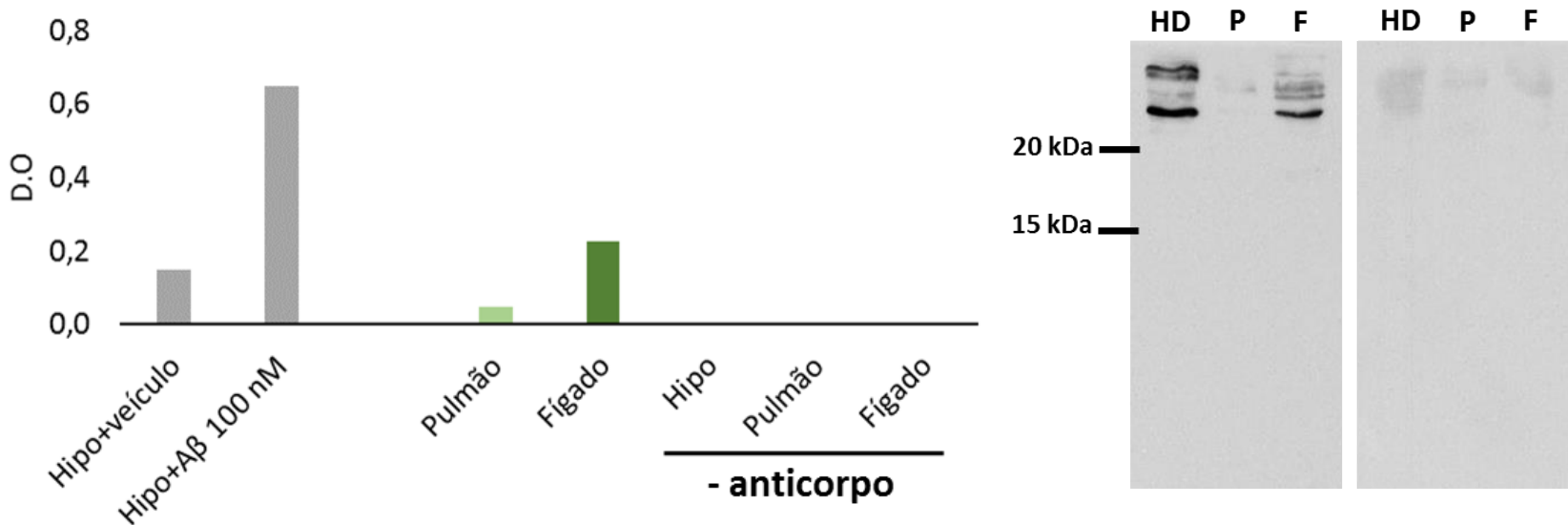

Figura 9 - Detecção do peptídeo $\beta$-amiloide (Aß) em extratos de hipocampo dorsal de ratos adultos (12 meses). A: detecção do peptídeo $\mathrm{A} \beta$ em hipocampo dorsal de ratos Wistar e WAR por ELISA sandwich, utilizando os anticorpos anti- $\beta$-amiloide (DE2B4) e anti- $\beta$-amiloide (22-35) para captura e detecção, respectivamente. B: teste de especificidade de ligação do anticorpo de detecção anti- $\beta$-amiloide (22-35) por ELISA. C: teste de especificidade dos anticorpos anti- $\beta$-amiloide usados, por Western Blotting. Extratos de hipocampo dorsal (HD), pulmão (P) e fígado (F) de ratos Wistar de 12 meses foram testados. 


\section{DISCUSSÃO}

No presente estudo, buscou-se avaliar se os animais da cepa WAR apresentam as características comportamentais e os marcadores bioquímicos típicos da doença de Alzheimer, necessários para caracterizar esta cepa como um modelo experimental adequado para o estudo da comorbidade entre a doença de Alzheimer e epilepsia, já que, em caso positivo, esse poderia ser o primeiro modelo animal não-modificado geneticamente e livre do uso de convulsivantes químicos ou elétricos.

Os dados de análise comportamental obtidos confirmam relatos prévios de que os animais da cepa WAR apresentam distúrbios na capacidade de aprendizagem e de memória espacial. Cunha e colaboradores (2015) haviam demonstrado, também pelo teste labirinto aquático de Morris (LAM), que animais WAR jovens (2 meses) já apresentam déficits endógenos de memória em relação aos animais Wistar controles de idade pareada, independente da exposição prévia dos ratos ao protocolo de estimulação sonora de alta intensidade (kindling audiogênico), capaz de provocar crises epiléticas audiogênicas. Outros dados obtidos pelo nosso grupo de pesquisa usando o teste de reconhecimento de objetos, ainda não publicados, corroboram a hipótese de déficits precoces de memória nos animais da cepa WAR, visto estes animais passam a ser incapazes de fazer distinção entre os objetos novo e velho já aos 7 meses de idade, enquanto esse fenômeno só é observado nos animais Wistar aos 12 meses. No presente estudo, um aspecto que merece destaque, e que reforça a ideia de que os animais WAR realmente possuem distúrbios na capacidade de evocação de memória, é o fato de que, mesmo que os animais tenham sido submetidos ao LAM aos 9 meses de idade e reexpostos a este teste 3 meses depois (aos 12 meses), ainda foi possível detectar aumento na latência de fuga e distância navegada nos WAR, nos blocos 2 e 3 da fase de aprendizagem, quando comparados aos Wistar, o que indica que a exposição prévia ao teste não facilitou tanto a realização desta tarefa quanto o fez para os ratos Wistar. No entanto, para o teste de retenção de memória, realizado após a segunda exposição dos ratos à fase de aprendizagem, não houve diferenças no desempenho entre as cepas, provavelmente porque a tarefa se tornou muito fácil devido ao grande número de repetições realizadas ao longo de todo o processo.

Como já está bem estabelecido que as alterações neuropatológicas e bioquímicas no cérebro de portadores da doença de Alzheimer surgem antes mesmo do aparecimento dos 
primeiros sintomas comportamentais, como perda de memória (SERRANO-POZO et al., 2011), buscou-se avaliar nos animais da cepa WAR a presença dos principais marcadores bioquímicos da DA que pudessem fornecer, ao menos parcialmente, fundamentação para a presença dos déficits de memória e aprendizado observados no LAM. Inicialmente, o objetivo deste estudo foi detectar e quantificar os níveis gerais da proteína Tau, hiperfosforilada e total, em extratos de hipocampo de animais da cepa WAR, pois esta é a principal estrutura cerebral envolvida na formação de memórias episódicas e de referência espacial (LEUNER; GOULD, 2010), e que, portanto, mais possui relação com os déficits de memória espacial observados, além de ser geralmente a primeira e mais acometida das estruturas cerebrais na DA (SERRANO-POZO et al., 2011; SCHÖLL et al., 2016). O mesmo foi feito em extratos de córtex pré-frontal, visto que esta região cerebral está envolvida, dentre outras coisas, no processamento de informações e memórias hierarquicamente organizadas, necessárias para a tomada de decisões, e juntamente com o hipocampo, exerce papel fundamental na cognição espacial e planejamento de ações (JO et al., 2007; MARTINET et al., 2011). Na literatura, já foi amplamente demonstrada a consistência da correlação entre o aumento dos níveis de pTau e a presença de neurodegeneração e/ou déficits cognitivos. Desta forma, os dados obtidos no presente estudo corroboram estes relatos, visto que foi observado um aumento significativo nos níveis gerais de pTau no hipocampo de animais WAR, os quais já haviam apresentado déficits cognitivos. Além disso, o aumento também observado nos níveis de Tau total nesta região pode ser interpretado como uma tentativa de manutenção das funções normais por parte dos neurônios afetados, através do aumento da síntese de Tau, já que a hiperfosforilação desta proteína reduz os níveis da fração normofosforilada, por meio de agregação, causando prejuízos na montagem e estabilização de microtúbulos, já que a Tau agregada é incapaz de realizar estas funções. Esse mecanismo é visto, por exemplo, na taupatia relacionada à DA (IQBAL; LIU; GONG, 2016). A inexistência de diferença na relação pTau/Tau total entre os grupos indica que o aumento de pTau foi proporcional ao aumento de Tau total no hipocampo dos animais WAR, fato sugestivo de que realmente houve uma tentativa de manutenção dos níveis fisiológicos do pool de Tau funcional (ou normal) nos neurônios. No entanto, isso não os isenta de sofrerem neurodegeneração, pois o acúmulo e agregação contínua de pTau acarreta a formação de emaranhados neurofibrilares insolúveis cada vez maiores no interior dos neurônios, os quais podem interferir com o funcionamento celular à medida que constituem barreiras físicas, por se tratarem de lesões que ocupam muito espaço (BALLATORE; LEE; TROJANOWSKI, 2007; GENDRON; PETRUCELLI, 2009). Além do hipocampo, alguns estudos já demonstraram que também ocorre aumento marcante de 
hiperfosforilação de Tau no córtex pré-frontal de portadores da DA, podendo chegar em níveis até 8 vezes maiores, em estágios mais avançados da doença, quando comparados aos pacientes controle (KHATOON; GRUNDKE-IQBAL; IQBAL, 1992; SERRANO-POZO et al., 2011). No entanto, os dados obtidos no presente estudo não demonstraram diferenças significativas entre as cepas no que diz respeito aos níveis de pTau e Tau total no córtex préfrontal, apesar de haver uma tendência estatística de aumento de pTau nos animais da cepa WAR. Como mencionado anteriormente, na DA, a primeira região acometida pelas alterações neuropatológicas e bioquímicas é o hipocampo, e à medida que a doença progride, essas alterações vão se disseminando para outras regiões cerebrais, como o córtex pré-frontal, por exemplo (SERRANO-POZO et al., 2011; SCHÖLL et al., 2016). Portanto, é possível que a não-detecção de hiperfosforilação de Tau no córtex dos animais da cepa WAR seja realmente por conta de uma questão temporal, em que os animais de 12 meses ainda não alcançaram um estágio avançado que leva ao acumulo robusto de pTau no cortex frontal.

Um fenômeno que ocorre em conjunto com a hiperfosforilação de Tau é a sua redistribuição anômala entre os compartimentos neuronais, visto que em condições fisiológicas, esta proteína está predominantemente localizada nos axônios de neurônios maduros. Entretanto, um dos marcadores neuropatológicos clássicos presentes no desenvolvimento de taupatias, incluindo a relacionada à DA, é a redistribuição de Tau hiperfosforilada para o compartimento somatodendrítico (ANDORFER et al., 2003; NOBLE et al., 2013). Além disso, um estudo realizado por Seifan e colaboradores (2015) mostrou que, em portadores da DA, a distribuição de pTau nas sub-regiões hipocampais ocorre em padrões variados, dependendo do estágio de severidade da doença, o que possivelmente reflete envolvimentos regionais diferenciados ao longo da progressão. Neste estudo, verificou-se que nos casos em que a taupatia era proeminente tanto na lâmina interna quanto externa da camada molecular do giro denteado, havia maior associação com diagnóstico definitivo da DA e precocidade de surgimento dos sintomas, em comparação aos casos em que pTau era proeminente apenas em uma das lâminas, ou aos casos em que havia baixa densidade de marcação de pTau em abas as lâminas avaliadas. Considerando-se este aspecto, os dados de imunoistoquímica obtidos no presente estudo contribuem para o fornecimento de informações a respeito da distribuição sub-regional da proteína pTau no hipocampo dos animais da cepa WAR, e mostram que o padrão de imuno-marcação obtido se assemelha ao que foi observado para os portadores da DA em estágios moderadamente avançados (SEIFAN et al., 2015). 
De forma inesperada, foi demonstrado que os níveis de pTau nos animais com 3-5 meses estavam mais elevados na cepa Wistar do que nos WAR, em todas as regiões quantificadas. Este resultado ainda não possui uma explicação clara, porém, há a possibilidade de ser consequência de algum artefato técnico, eventualmente provocado por erros durante a execução do procedimento de imunoistoquímica em si, ou mesmo em etapas prévias, como armazenamento dos tecidos ou preparo de soluções utilizadas no experimento, por exemplo. De fato, as secções de hipocampo utilizadas para a realização desta imunoistoquímica já estavam armazenadas desde 2013 (nas condições descritas na seção de material e métodos), o que constitui uma variável extra que pode, ou não, ter influência no estado de conservação e exposição dos epítopos do tecido. Por isso, reconhecemos que existe a necessidade de repetição deste experimento, usando tecidos recém-coletados, para a verificação da consistência e reprodutibilidade dos resultados obtidos anteriormente. No caso de persistência de maiores níveis de pTau em animais Wistar de 3-5 meses em relação aos WAR de mesma idade, seria necessária a realização de uma avaliação secundária, com o intuito de descobrir se este é um fenômeno realmente comum em animais da linhagem Wistar em geral, ou se é específico apenas para os animais Wistar obtidos do biotério central da USP de Ribeirão Preto.

O segundo biomarcador clássico da DA alvo desse estudo foi o peptídeo $\beta$-amiloide (A $\beta$ ). Da mesma forma que a proteína Tau, o objetivo foi detectar e quantificar os níveis de $\mathrm{A} \beta$ em extratos de hipocampo dorsal de animais da cepa WAR adultos. Através do ensaio de ELISA, utilizando os anticorpos anti- $\beta$-amiloide (DE2B4) e anti- $\beta$-amiloide (22-35) para captura e detecção, respectivamente, foi detectado sinal para as amostras de hipocampo de ratos Wistar e WAR, bem como para as amostras que receberam adição de A $\beta-42$ humano sintético. No entanto, não é possível afirmar que este sinal era realmente específico para $\mathrm{A} \beta$, pois em um dos controles obteve-se sinal significativo em extrato de fígado, um tecido em que não expressa a proteína APP. Por outro lado, o Western Blotting demonstrou que nenhum dos anticorpos utilizados foi capaz de detectar a banda de aproximadamente 4,5 kDa relativa a monômeros de $A \beta$ endógeno de ratos, sendo observada apenas a presença de bandas de 25 kDa ou mais pesadas, fato que confere força à hipótese de que os sinais detectados no ensaio de ELISA não correspondem ao $A \beta$ endógeno. É possível que a falta de êxito em detectar monômeros de A $\beta$ endógeno, pelas estratégias empregadas, decorra da incapacidade dos anticorpos utilizados em reconhecer esta proteína proveniente de roedores, já que a mesma possui algumas modificações na sua sequência primária em relação à ortologa de humanos, e 
esta última é detectável pelos anticorpos anti- $\beta$-amiloide (DE2B4) e (22-35) via Western Blotting (dados não mostrados). Outra possibilidade a ser considerada é que os monômeros de $\mathrm{A} \beta$ endógeno de roedores podem ser pouco abundantes, ou mesmo podem estar solúveis, nos extratos utilizados, apenas em concentrações abaixo do limiar de detecção da técnica de Western Blotting, devido à sua maior tendência de agregação em espécies complexas como protofibrilas e fibras (ROYCHAUDHURI et al., 2015), que são insolúveis e resistentes à ação dos agentes caotrópicos normalmente utilizados para o preparo dos extratos e das amostras para o SDS-PAGE (SHANKAR et al., 2008). Desta forma, fica evidente a necessidade de utilização de estratégias alternativas para a detecção da proteína $A \beta$ de ratos, já que se trata de um dos biomarcadores clássicos da DA e, portanto, fundamental para a caracterização desta patologia como comorbidade presente na cepa WAR.

Em resumo, no presente estudo, verificou-se que os animais adultos da cepa WAR apresentam algumas características comportamentais semelhantes às observadas em pacientes portadores da doença de Alzheimer, que são os déficits de aprendizagem e de memória espacial, além da presença de um dos biomarcadores celulares clássicos desta doença neuropsiquiátrica, que é a elevação nos níveis da proteína Tau hiperfosforilada no hipocampo destes animais, o qual foi acompanhado por um aumento dos níveis de Tau total. Foi verificado, ainda, a ocorrência de redistribuição da Tau hiperfosforilada em determinadas subregiões hipocampais, que também constitui um marco do desenvolvimento de taupatia típica de portadores da doença de Alzheimer em estágios moderadamente avançados. Quando analisados em conjunto, os dados sugerem que os déficits de memória observados nos animais WAR podem ser reflexo da hiperfosforilação e consequente distribuição anormal da proteína Tau, por um mecanismo molecular a ser desvendado. Não foi possível determinar se este mecanismo inclui aumento nos níveis de agregados de A $\beta$. Desta forma, é possível inferir que a caracterização da cepa WAR como modelo experimental para o estudo da comorbidade entre a doença de Alzheimer e epilepsia se mostra promissora, porém não concluída, visto que ainda há a necessidade de elaboração de uma estratégia que permita a detecção e dosagem da proteína $\beta$-amiloide endógena em amostras de tecido cerebral destes animais, como esperado de modelos experimentais da doença de Alzheimer. 


\section{CONCLUSÃO}

Os dados obtidos no presente estudo indicam que os animais da cepa WAR apresentam algumas características comportamentais e bioquímicas típicas da doença de Alzheimer, e o seu emprego como modelo experimental para o estudo dos fenômenos moleculares subjacentes à comorbidade desta doença com a epilepsia se mostra promissor, porém, ainda precisa ser melhor caracterizado, já que existem questões importantes ainda não elucidadas e que, portanto, impedem a validação do fenótipo apresentado pelos animais WAR como sendo típico da doença de Alzheimer. 


\section{REFERÊNCIAS BIBLIOGRÁFICAS}

AHMED, M. et al. Structural conversion of neurotoxic amyloid-[beta] 1-42 oligomers to fibrils. Nature structural \& molecular biology, v. 17, n. 5, p. 561-567, 2010.

AMATNIEK, J. C. et al. Incidence and predictors of seizures in patients with Alzheimer's disease. Epilepsia, v. 47, n. 5, p. 867-872, 2006.

ANDERTON, B. H. et al. Sites of phosphorylation in tau and factors affecting their regulation. In: Biochemical Society Symposia. Portland Press Limited, 2001. p. 73-80.

ANDORFER, C. et al. Hyperphosphorylation and aggregation of tau in mice expressing normal human tau isoforms. Journal of neurochemistry, v. 86, n. 3, p. 582-590, 2003.

ARAI, H. et al. Expression patterns of $\beta$-amyloid precursor protein ( $\beta$-APP) in neural and nonneural human tissues from alzheimer's disease and control subjects. Annals of neurology, v. 30, n. 5, p. 686-693, 1991.

BÄCKMAN, L. et al. Multiple cognitive deficits during the transition to Alzheimer's disease. Journal of internal medicine, v. 256, n. 3, p. 195-204, 2004.

BALLATORE, C.; LEE, V. M. Y.; TROJANOWSKI, J. Q. Tau-mediated neurodegeneration in Alzheimer's disease and related disorders. Nature Reviews Neuroscience, v. 8, n. 9, p. 663-672, 2007.

BANDYOPADHYAY, B. et al. Tau aggregation and toxicity in a cell culture model of tauopathy. Journal of Biological Chemistry, v. 282, n. 22, p. 16454-16464, 2007.

BANNERMAN, D. M. et al. Hippocampal synaptic plasticity, spatial memory and anxiety. Nature Reviews Neuroscience, v. 15, n. 3, p. 181-192, 2014.

BEKRIS, L. M. et al. Review article: genetics of Alzheimer disease. Journal of geriatric psychiatry and neurology, v. 23, n. 4, p. 213-227, 2010.

BERCHTOLD, N. C.; COTMAN, C. W. Evolution in the conceptualization of dementia and Alzheimer's disease: Greco-Roman period to the 1960s. Neurobiology of aging, v. 19, n. 3, p. 173-189, 1998.

BERRIOS, G. E. Alzheimer's disease: a conceptual history. International Journal of Geriatric Psychiatry, v. 5, n. 6, p. 355-365, 1990.

BERNSTEIN, S. L. et al. Amyloid- $\beta$ protein oligomerization and the importance of tetramers and dodecamers in the aetiology of Alzheimer's disease. Nature chemistry, v. 1, n. 4, p. 326$331,2009$.

BITAN, G. et al. Amyloid $\beta$-protein $(A \beta)$ assembly: $A \beta 40$ and $A \beta 42$ oligomerize through distinct pathways. Proceedings of the National Academy of Sciences, v. 100, n. 1, p. 330335, 2003.

BLENNOW, K.; DE LEON, M. J.; ZETTERBERG, H. Alzheimer's Disease. Lancet, v. 368, p. 387-403, 2006. 
BOURAS, C. et al. Regional distribution of neurofibrillary tangles and senile plaques in the cerebral cortex of elderly patients: a quantitative evaluation of a one-year autopsy population from a geriatric hospital. Cerebral cortex, v. 4, n. 2, p. 138-150, 1994.

BRAAK, H.; BRAAK, E. Neuropathological stageing of Alzheimer-related changes. Acta neuropathologica, v. 82, n. 4, p. 239-259, 1991.

BRADFORD, M. M. A rapid and sensitive method for the quantitation of microgram quantities of protein utilizing the principle of protein-dye binding. Analytical Biochemistry, v. 72, n. 1-2, p. 248-254, 1976.

BRAMBLETT, G. T. et al. Abnormal tau phosphorylation at Ser 396 in Alzheimer's disease recapitulates development and contributes to reduced microtubule binding. Neuron, v. 10, n. 6, p. 1089-1099, 1993.

BRUNNSTRÖM, H. R.; ENGLUND, E. M. Cause of death in patients with dementia disorders. European journal of neurology, v. 16, n. 4, p. 488-492, 2009.

BUCKMASTER, P. S.; DUDEK, F. E. Neuron loss, granule cell axon reorganization, and functional changes in the dentate gyrus of epileptic kainate-treated rats. Journal of Comparative Neurology, v. 385, n. 3, p. 385-404, 1997.

BUCKMASTER, P. S.; INGRAM, E. A.; WEN, X. Inhibition of the mammalian target of rapamycin signaling pathway suppresses dentate granule cell axon sprouting in a rodent model of temporal lobe epilepsy. Journal of Neuroscience, v. 29, n. 25, p. 8259-8269, 2009.

BUSCHE, M. A. et al. Clusters of hyperactive neurons near amyloid plaques in a mouse model of Alzheimer's disease. Science, v. 321, n. 5896, p. 1686-1689, 2008.

CARLESIMO, G. A.; OSCAR-BERMAN, M. Memory deficits in Alzheimer's patients: a comprehensive review. Neuropsychology review, v. 3, n. 2, p. 119-169, 1992.

CHAKRABARTI, S. et al. Metabolic risk factors of sporadic Alzheimer's disease: implications in the pathology, pathogenesis and treatment. Aging and disease, v. 6, n. 4, p. $282,2015$.

CHIEN, D. T. et al. Early clinical PET imaging results with the novel PHF-tau radioligand [F18]-T807. Journal of Alzheimer's Disease, v. 34, n. 2, p. 457-468, 2013.

CONDE, C.; CÁCERES, A. Microtubule assembly, organization and dynamics in axons and dendrites. Nature reviews. Neuroscience, v. 10, n. 5, p. 319-332, 2009.

COOK, et al. Hippocampal volumetric and morphometric studies in frontal and temporal lobe epilepsy. Brain, v. 115, n. 4, p. 1001-1015, 1992.

CUNHA, A. O. S. et al. Inhibition of long-term potentiation in the schaffer-CA1 pathway by repetitive high-intensity sound stimulation. Neuroscience, v. 310, p. 114-127, 2015.

DESHPANDE, A. et al. Different conformations of amyloid $\beta$ induce neurotoxicity by distinct mechanisms in human cortical neurons. Journal of Neuroscience, v. 26, n. 22, p. 6011-6018, 2006.

DICKSTEIN, D. L. et al. Changes in dendritic complexity and spine morphology in transgenic mice expressing human wild-type tau. Brain Structure and Function, v. 214, n. 2-3, p. 161-179, 2010.

DINIZ, B. S. et al. Late-life depression and risk of vascular dementia and Alzheimer's 
disease: systematic review and meta-analysis of community-based cohort studies. The British Journal of Psychiatry, v. 202, n. 5, p. 329-335, 2013.

DORETTO, M. C. et al. Quantitative study of the response to genetic selection of the Wistar audiogenic rat strain (WAR). Behavior genetics, v. 33, n. 1, p. 33-42, 2003.

DOUAUD, G. et al. A common brain network links development, aging, and vulnerability to disease. Proceedings of the National Academy of Sciences, v. 111, n. 49, p. 17648-17653, 2014.

DUERING, M. et al. Mean age of onset in familial Alzheimer's disease is determined by amyloid beta 42. Neurobiology of aging, v. 26, n. 6, p. 785-788, 2005.

ECONOMOU, N. J. et al. Amyloid $\beta$-protein assembly and Alzheimer's disease: Dodecamers of a $\beta 42$, but not of a $\beta 40$, seed fibril formation. Journal of the American Chemical Society, v. 138, n. 6, p. 1772-1775, 2016.

EIKELENBOOM, P. et al. Complement activation in amyloid plaques in Alzheimer's dementia. Virchows Archiv B Cell Pathology Zell-pathologie, v. 56, n. 1, p. 259-262, 1988.

EMMERLING, M. R. et al. The role of complement in Alzheimer's disease pathology. Biochimica et Biophysica Acta (BBA)-Molecular Basis of Disease, v. 1502, n. 1, p. 158-171, 2000.

FAZAN, R. et al. Changes in autonomic control of the cardiovascular system in the Wistar audiogenic rat (WAR) strain. Epilepsy \& Behavior, v. 22, n. 4, p. 666-670, 2011.

FIGUEIREDO, C. P. et al. Memantine rescues transient cognitive impairment caused by highmolecular-weight a $\beta$ oligomers but not the persistent impairment induced by low-molecularweight oligomers. Journal of Neuroscience, v. 33, n. 23, p. 9626-9634, 2013.

FÖRSTL, H.; KURZ, A. Clinical features of Alzheimer's disease. European archives of psychiatry and clinical neuroscience, v. 249, n. 6, p. 288-290, 1999.

GAITATZIS, A. et al. The epidemiology of the comorbidity of epilepsy in the general population. Epilepsia, v. 45, n. 12, p. 1613-1622, 2004.

GALVIS-ALONSO, O. Y.; OLIVEIRA, J. A. C.; GARCIA-CAIRASCO, N. Limbic epileptogenicity, cell loss and axonal reorganization induced by audiogenic and amygdala kindling in Wistar audiogenic rats (WAR strain). Neuroscience, v. 125, n. 3, p. 787-802, 2004.

GARCEZ, M. L. et al. Alzheimer' s Disease associated with Psychiatric Comorbidities. Anais da Academia Brasileira de Ciências, v. 87, n. 2, p. 1461-1473, 2015.

GARCIA-CAIRASCO, N.; SABBATINI, R. M. Role of the substantia nigra in audiogenic seizures: a neuroethological analysis in the rat. Brazilian journal of medical and biological research. v. 16, n. 2, p. 171-183, 1983.

GARCIA-CAIRASCO, N.; TERRA, V. C.; DORETTO, M. C. Midbrain substrates of audiogenic seizures in rats. Behavioural brain research, v. 58, n. 1, p. 57-67, 1993.

GARCIA-CAIRASCO, N. et al. Brainstem forebrain interactions during audiogenic kindling: an integrated video-EEG, neuroethology and fos protein expression study. In: Soc. Neurosci. Abstr. v. 22, . p. 2092, 1996.a.

GARCIA-CAIRASCO, N. et al. Neuroethological and morphological (Neo-Timm staining) 
correlates of limbic recruitment during the development of audiogenic kindling in seizure susceptible Wistar rats. Epilepsy research, v. 26, n. 1, p. 177-192, 1996.b.

GARCIA-CAIRASCO, N. et al. Reduced exploratory activity of audiogenic seizures suceptible Wistar rats. Physiology \& behavior, v. 64, n. 5, p. 671-674, 1998.

GASPAR, R. C. et al. Oligomers of $\beta$-amyloid are sequestered into and seed new plaques in the brains of an AD mouse model. Experimental neurology, v. 223, n. 2, p. 394-400, 2010.

GENDRON, T. F.; PETRUCELLI, L. The role of tau in neurodegeneration. Molecular neurodegeneration, v. 4, n. 1, p. 13, 2009.

GEORGE-HYSLOP, P. H. St. et al. The genetic defect causing familial Alzheimer's disease maps on chromosome 21. Science, v. 235, p. 885-891, 1987.

GOEDERT, M. et al. Cloning and sequencing of the cDNA encoding an isoform of microtubule-associated protein tau containing four tandem repeats: differential expression of tau protein mRNAs in human brain. The EMBO journal, v. 8, n. 2, p. 393, 1989.

GONG, Y. et al. Alzheimer's disease-affected brain: presence of oligomeric A $\beta$ ligands (ADDLs) suggests a molecular basis for reversible memory loss. Proceedings of the National Academy of Sciences, v. 100, n. 18, p. 10417-10422, 2003.

GRANJEIRO, E. M. et al. Behavioral, Ventilatory and Thermoregulatory Responses to Hypercapnia and Hypoxia in the Wistar Audiogenic Rat (WAR) Strain. PloS one, v. 11, n. 5, p. e0154141, 2016.

HANGER, D. et al. New phosphorylation sites identified in hyperphosphorylated tau (paired helical filament-tau) from Alzheimer's disease brain using nanoelectrospray mass spectrometry. Journal of neurochemistry, v. 71, n. 6, p. 2465-2476, 1998.

HAUPT, M.; KURZ, A. Predictors of nursing home placement in patients with Alzheimer's disease. International Journal of Geriatric Psychiatry, v. 8, n. 9, p. 741-746, 1993.

HAUSER, W. A. et al. Seizures and myoclonus in patients with Alzheimer's disease. Neurology, v. 36, n. 9, p. 1226-1226, 1986.

HEAD, E. et al. Alzheimer's disease in Down syndrome. European journal of neurodegenerative disease, v. 1, n. 3, p. 353, 2012.

HENZE, D. A.; URBAN, N. N.; BARRIONUEVO, G. The multifarious hippocampal mossy fiber pathway: a review. Neuroscience, v. 98, n. 3, p. 407-427, 2000.

HESDORFFER, D. C. et al. Dementia and adult-onset unprovoked seizures. Neurology, v. 46, n. 3, p. 727-730, 1996.

HIPPIUS, H.; NEUNDÖRFER, G. The discovery of Alzheimer's disease. Dialogues in clinical neuroscience, v. 5, n. 1, p. 101, 2003.

IKEDA, T.; YAMADA, M. Risk factors for Alzheimer's disease. Brain and nerve $=$ Shinkei kenkyu no shinpo, v. 62, n. 7, p. 679-690, 2010.

IQBAL, K. et al. Tau pathology in Alzheimer disease and other tauopathies. Biochimica et Biophysica Acta (BBA)-Molecular Basis of Disease, v. 1739, n. 2, p. 198-210, 2005.

IQBAL, K.; LIU, F.; GONG, C. X. Tau and neurodegenerative disease: the story so far. Nature Reviews Neurology, v. 12, n. 1, p. 15-27, 2016. 
ISIK, A. T. Late onset Alzheimer's disease in older people. Clinical interventions in aging, v. 5, p. 307, 2010.

JEGANATHAN, S. et al. Proline-directed pseudo-phosphorylation at AT8 and PHF1 epitopes induces a compaction of the paperclip folding of Tau and generates a pathological (MC-1) conformation. Journal of Biological Chemistry, v. 283, n. 46, p. 32066-32076, 2008.

JO, Y. S. et al. The medial prefrontal cortex is involved in spatial memory retrieval under partial-cue conditions. Journal of Neuroscience, v. 27, n. 49, p. 13567-13578, 2007.

JOHNSON, K. A. et al. Brain imaging in Alzheimer disease. Cold Spring Harbor perspectives in medicine, v. 2, n. 4, p. a006213, 2012.

JOHNSON-WOOD, K. et al. Amyloid precursor protein processing and A $\beta 42$ deposition in a transgenic mouse model of Alzheimer disease. Proceedings of the National Academy of Sciences, v. 94, n. 4, p. 1550-1555, 1997.

KAYED, R.; LASAGNA-REEVES, C. A. Molecular mechanisms of amyloid oligomers toxicity. Journal of Alzheimer's Disease, v. 33, n. s1, p. S67-S78, 2013.

KESSING, L. V.; ANDERSEN, P. K. Does the risk of developing dementia increase with the number of episodes in patients with depressive disorder and in patients with bipolar disorder?. Journal of Neurology, Neurosurgery \& Psychiatry, v. 75, n. 12, p. 1662-1666, 2004.

KHATOON, S.; GRUNDKE-IQBAL, I.; IQBAL, K. Brain Levels of Microtubule-Associated Protein $\tau$ Are Elevated in Alzheimer's Disease: A Radioimmuno-Slot-Blot Assay for Nanograms of the Protein. Journal of neurochemistry, v. 59, n. 2, p. 750-753, 1992.

KLYBIN, I. et al. A $\beta$ dimer-containing human cerebrospinal fluid disrupts synaptic plasticity: prevention by systemic passive immunization. J Neurosci, v. 28, p. 4231-4237, 2008.

KOFFIE, R. M. et al. Oligomeric amyloid $\beta$ associates with postsynaptic densities and correlates with excitatory synapse loss near senile plaques. Proceedings of the National Academy of Sciences, v. 106, n. 10, p. 4012-4017, 2009.

KOWALSKA, A. The beta-amyloid cascade hypothesis: a sequence of events leading to neurodegeneration in Alzheimer's disease. Neurologia i neurochirurgia polska, v. 38, n. 5, p. 405-411, 2003.

LACOR, P. N. et al. A $\beta$ oligomer-induced aberrations in synapse composition, shape, and density provide a molecular basis for loss of connectivity in Alzheimer's disease. Journal of Neuroscience, v. 27, n. 4, p. 796-807, 2007.

LAFERLA, F. M.; GREEN, K. N.; ODDO, S. Intracellular amyloid- $\beta$ in Alzheimer's disease. Nature Reviews Neuroscience, v. 8, n. 7, p. 499-509, 2007.

LAMBERT, M. P. et al. Diffusible, nonfibrillar ligands derived from A $\beta 1-42$ are potent central nervous system neurotoxins. Proceedings of the National Academy of Sciences, v. 95, n. 11, p. 6448-6453, 1998.

LANDES, A. M. et al. Apathy in Alzheimer's disease. Journal of the American Geriatrics Society, v. 49, n. 12, p. 1700-1707, 2001.

LASAGNA-REEVES, C. A. et al. Identification of oligomers at early stages of tau aggregation in Alzheimer's disease. The FASEB Journal, v. 26, n. 5, p. 1946-1959, 2012. 
LESNÉ, S. et al. A specific amyloid- $\beta$ protein assembly in the brain impairs memory. Nature, v. 440, n. 7082, p. 352-357, 2006.

LEUNER, B.; GOULD, E. Structural plasticity and hippocampal function. Annual review of psychology, v. 61, p. 111-140, 2010.

LI, M. et al. The role of intracellular amyloid $\beta$ in Alzheimer's disease. Progress in neurobiology, v. 83, n. 3, p. 131-139, 2007.

LÓPEZ-LÓPEZ, D. et al. Overexpression of the immediate-early genes Egr1, Egr2, and Egr3 in two strains of rodents susceptible to audiogenic seizures. Epilepsy \& Behavior, 2016.

LOZSADI, D. A.; LARNER, A. J. Prevalence and causes of seizures at the time of diagnosis of probable Alzheimer's disease. Dementia and geriatric cognitive disorders, v. 22, n. 2, p. 121-124, 2006.

MAHLEY, R. W.; WEISGRABER, K. H.; HUANG, Y. Apolipoprotein E4: a causative factor and therapeutic target in neuropathology, including Alzheimer's disease. Proceedings of the National Academy of Sciences, v. 103, n. 15, p. 5644-5651, 2006.

MARESCAUX, C. et al. Kindling of audiogenic seizures in Wistar rats: an EEG study. Experimental neurology, v. 97, n. 1, p. 160-168, 1987.

MARINESCO, B. Sur les lésions et la pathogénie de l'épilepsie dite essentielle. Sem. méd, p. $445,1892$.

MARRONI, S. S. et al. Oxytocin-induced Hypergrooming In The Wistar Audiogenic Rat (war) Strain: Modeling Compulsion And Epilepsy Co-morbidities. Epilepsia, v. 50, p. 338, 2009.

MARTINET, L. E. et al. Spatial learning and action planning in a prefrontal cortical network model. PLoS Comput Biol, v. 7, n. 5, p. e1002045, 2011.

MORRIS, R. G. M. Spatial localization does not require the presence of local cues. Learning and motivation, v. 12, n. 2, p. 239-260, 1981.

MURPHY, M. P.; LEVINE III, H. Alzheimer's disease and the $\beta$-amyloid peptide. J Alzheimers Dis, v. 19, n. 1, p. 311-323, 2010.

NAGAISHI, M. et al. An immunohistochemical finding in glioneuronal lesions associated with epilepsy: The appearance of nestin-positive, CD34-positive and tau-accumulating cells. Neuropathology, v. 31, n. 5, p. 468-475, 2011.

NICOLL, J. A. R. Neuropathology: A Reference Text of CNS Pathology. Neuropathology and Applied Neurobiology, v. 31, n. 1, p. 102-102, 2005.

NOBLE, W. et al. The importance of tau phosphorylation for neurodegenerative diseases. Frontiers in neurology, v. 4, 2013.

NYGÅRD, L. Instrumental activities of daily living: a stepping-stone towards Alzheimer's disease diagnosis in subjects with mild cognitive impairment?. Acta Neurologica Scandinavica, v. 107, n. s179, p. 42-46, 2003.

OKAZAKI, M. M.; MOLNÁR, P.; NADLER, J. V. Recurrent mossy fiber pathway in rat dentate gyrus: synaptic currents evoked in presence and absence of seizure-induced growth. Journal of neurophysiology, v. 81, n. 4, p. 1645-1660, 1999. 
OLIVEIRA, J. A. C. et al. The Wistar Audiogenic Rat (WAR) strain: A Genetic Model to Study Neuropsychiatry Comorbidities in the Epilepsies (I). Memory Performance. $1^{\text {st }}$ Audiogenic Epilepsy Congr., Salamanca, 2014.

PALOP, J. J. et al. Aberrant excitatory neuronal activity and compensatory remodeling of inhibitory hippocampal circuits in mouse models of Alzheimer's disease. Neuron, v. 55, n. 5, p. 697-711, 2007.

PATTERSON, K. R. et al. Characterization of prefibrillar Tau oligomers in vitro and in Alzheimer disease. Journal of Biological Chemistry, v. 286, n. 26, p. 23063-23076, 2011.

PAXINOS, G.; WATSON, C. The rat brain in stereotaxic coordinates. 4. ed. San Diego: Academic Press, 1998.

PERRY, E. K. et al. Visual hallucinations and the cholinergic system in dementia. Journal of Neurology, Neurosurgery \& Psychiatry, v. 53, n. 1, p. 88, 1990.

PETRY, F. R. et al. Specificity of anti-tau antibodies when analyzing mice models of Alzheimer's disease: problems and solutions. PloS one, v. 9, n. 5, p. e94251, 2014.

PRINCE, M. World Alzheimer Report. 2015.

ROMANELLI, M. F. et al. Advanced Alzheimer's disease is a risk factor for late-onset seizures. Archives of neurology, v. 47, n. 8, p. 847-850, 1990.

ROMCY-PEREIRA, R. N.; GARCIA-CAIRASCO, N. Hippocampal cell proliferation and epileptogenesis after audiogenic kindling are not accompanied by mossy fiber sprouting or Fluoro-Jade staining. Neuroscience, v. 119, n. 2, p. 533-546, 2003.

ROYCHAUDHURI, R. et al. Role of species-specific primary structure differences in A $\beta 42$ assembly and neurotoxicity. ACS chemical neuroscience, v. 6, n. 12, p. 1941-1955, 2015.

SAYRE, L. M. et al. Metal ions and oxidative protein modification in neurological disease. Annali dell'Istituto superiore di sanita, v. 41, n. 2, p. 143-164, 2004.

SCHAEFER, C. et al. Exogenous induction of cerebral beta-amyloidogenesis is governed by agent and host. Science, v. 313, p. 17811784Moechars, 2006.

SCHÖLL, M. et al. PET imaging of tau deposition in the aging human brain. Neuron, v. 89, n. 5, p. 971-982, 2016.

SEBOLLELA, A. et al. Amyloid- $\beta$ oligomers induce differential gene expression in adult human brain slices. Journal of Biological Chemistry, v. 287, n. 10, p. 7436-7445, 2012.

SEIFAN, A. et al. Hippocampal Laminar Distribution of Tau Relates to Alzheimer's Disease and Age of Onset. Journal of Alzheimer's Disease, v. 43, n. 1, p. 315-324, 2015.

SELKOE, D. J. Alzheimer's disease: genes, proteins, and therapy. Physiological reviews, v. 81, n. 2, p. 741-766, 2001.

SERENIKI, A.; VITAL, M. A. B. F. A doença de Alzheimer: aspectos fisiopatológicos e farmacológicos. Rev Psiquiatr RS, v. 30, n. 1, 2008.

SERRANO-POZO, A. et al. Neuropathological alterations in Alzheimer disease. Cold Spring Harbor perspectives in medicine, v. 1, n. 1, p. a006189, 2011.

SHANKAR, G. M. et al. Amyloid- $\beta$ protein dimers isolated directly from Alzheimer's brains impair synaptic plasticity and memory. Nature medicine, v. 14, n. 8, p. 837-842, 2008. 
SHARMA, A. et al. Dysregulation of mTOR signaling in fragile X syndrome. Journal of Neuroscience, v. 30, n. 2, p. 694-702, 2010.

SINGH, J. et al. Comparison of the phosphorylation of microtubule-associated protein tau by non-proline dependent protein kinases. Molecular and cellular biochemistry, v. 131, n. 2, p. 181-189, 1994.

SUPNET, C.; BEZPROZVANNY, I. The dysregulation of intracellular calcium in Alzheimer disease. Cell calcium, v. 47, n. 2, p. 183-189, 2010.

TAI, X. Y. et al. Hyperphosphorylated tau in patients with refractory epilepsy correlates with cognitive decline: a study of temporal lobe resections. Brain, p. aww187, 2016.

TANIGUCHI-WATANABE, S. et al. Biochemical classification of tauopathies by immunoblot, protein sequence and mass spectrometric analyses of sarkosyl-insoluble and trypsin-resistant tau. Acta neuropathologica, v. 131, n. 2, p. 267-280, 2016.

TIAN, F. et al. Potential roles of Cdk5/p35 and tau protein in hippocampal mossy fiber sprouting in the PTZ kindling model. Clinical laboratory, v. 56, n. 3-4, p. 127-136, 2009.

TOTOLA, L. T. et al. Impaired central respiratory chemoreflex in an experimental genetic model of epilepsy. The Journal of physiology, 2016.

TOWNSEND, M. et al. Effects of secreted oligomers of amyloid $\beta$-protein on hippocampal synaptic plasticity: a potent role for trimers. The Journal of physiology, v. 572, n. 2, p. 477492, 2006.

UMEOKA, E. H. L. et al. Functional characterization of the hypothalamic-pituitary-adrenal axis of the Wistar Audiogenic Rat (WAR) strain. Brain research, v. 1381, p. 141-147, 2011.

VLOOSWIJK, M. C. G. et al. Functional MRI in chronic epilepsy: associations with cognitive impairment. The Lancet Neurology, v. 9, n. 10, p. 1018-1027, 2010.

WALKER, L. C.; LEVINE 3rd, H. Proteopathy: the next therapeutic frontier? Current opinion in investigational drugs (London, England: 2000), v. 3, n. 5, p. 782-787, 2002.

WANG, Y.; MANDELKOW, E. Tau in physiology and pathology. Nature Reviews Neuroscience, 2015.

WENK, G. L. et al. Neuropathologic changes in Alzheimer's disease. Journal of Clinical Psychiatry, v. 64, p. 7-10, 2003.

WORLD HEALTH ORGANIZATION. Dementia Fact sheet $\mathbf{N}^{\circ} \mathbf{3 6 2}$. 2015. Obtido de: <https://web.archive.org/web/20150320121322/http://www.who.int:80/mediacentre/factsheets /fs362/en/>. Acesso em: 26 abr. 2017.

WU, J.; DICKSTEIN, D.; DUFF, K. Mechanism of tau transfer: insights from cell culture and animal models. Molecular Neurodegeneration, v. 8, n. 1, p. P50, 2013.

YAN, X. et al. Chronic temporal lobe epilepsy is associated with enhanced Alzheimer-like neuropathology in 3x Tg-AD mice. PloS one, v. 7, n. 11, p. e48782, 2012.

ZILKA, N. et al. Truncated tau from sporadic Alzheimer's disease suffices to drive neurofibrillary degeneration in vivo. FEBS letters, v. 580, n. 15, p. 3582-3588, 2006. 
ANEXO - Parecer da Comissão de Ética no Uso de Animais (CEUA-FMRP)
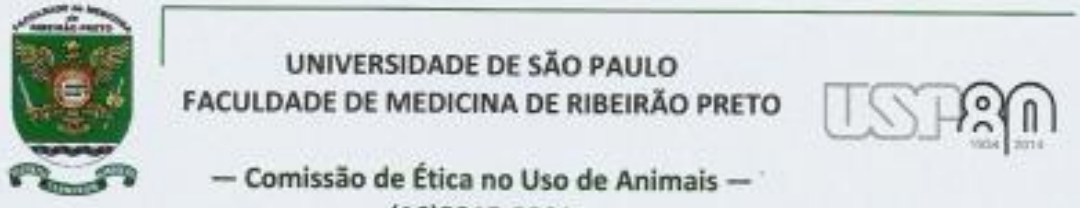

- Comissăo de Ética no Uso de Animais -

(16)3315-3301

\section{CERTIFICADO}

Certificamos que o Protocolo para Uso de Animais em Experimentaçåo $\mathrm{n}^{0} \mathbf{0 1 7 / 2 0 1 4 - 1}$, sobre o projeto intitulado "Bases moleculares da toxicidade de oligómeros proteicos associados à amiloidoses do sistema nervaso", sob a responsabilidade do Professor Doutor Adriano Silva Sebollela está de acordo com os Principios Éticos em Experimentação Animal adotado pelo Conselho Nacional de Controle de Experimentação Animal (CONCEA) e foi APROVADO em reunião de 29 de junho de 2015.

\footnotetext{
We certify that the protocol $n^{*} 017 / 2014-1$, sexitled "Molecular basis of she toxiciny of protein olligamers associated to brain anylowdosis", is in accordance with the Exhical Principles in Animal Research adopted by the National Council for the Conirol of Animal Experimentation (CONCEA) and was approved by the Local Animal Ethical Committee from the Ribeirlo Preto Medical School of the University of Säo Paclo in 06/29/2015.
}

Ribeirão Preto, 29 de junho de 2015.

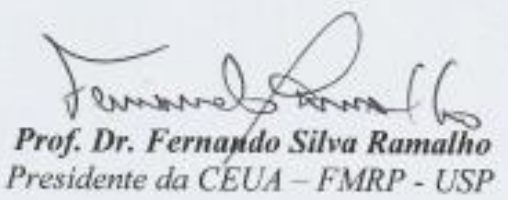

